\title{
Testing a Self-Affirmation Intervention for Improving the Psychosocial Health of Black and White Medical Students in the US
}

\author{
Sylvia P. Perry ${ }^{1}$, James E. Wages III' ${ }^{1}$, Allison L. Skinner-Dorkenoo ${ }^{2}$, Sara E. Burke ${ }^{3}$, Rachel R. \\ Hardeman $^{4}$, Sean M. Phelan 5 \\ ${ }^{1}$ Department of Psychology, Northwestern University \\ ${ }^{2}$ Department of Psychology, University of Georgia \\ ${ }^{3}$ Department of Psychology, Syracuse University \\ ${ }^{4}$ Division of Health Policy \& Management, University of Minnesota School of Public Health \\ ${ }^{5}$ Department of Health Services Research, Mayo Clinic
}

\begin{abstract}
Author Note
Sylvia P. Perry is an assistant professor of psychology and medical social sciences (by courtesy), and an Institute for Policy Research Faculty Associate at Northwestern University. She received her PhD in psychology from the University of Illinois at Chicago. Through her research, she seeks to understand how we can reduce intergroup biases, and how people cope with experiences of stigma and discrimination.
\end{abstract}

James E. Wages III is a Ph.D. candidate in social psychology at Northwestern University. James researches concepts broadly at the intersection of social stereotypes, lay theories, and risk-taking and how these phenomena influence pressing social, health, and 
achievement outcomes. His primary work investigates how people make meaning of risk-taking and whether such meanings are imbued with race and gender stereotype content.

Allison L. Skinner-Dorkenoo is an assistant professor of psychology at the University of Georgia. She received her PhD in psychology from the University of Nebraska-Lincoln and completed postdoctoral training positions at the University of Washington and Northwestern University. Her research examines how prejudice is established, maintained, and facilitated through situational cues in our social environments. Her primary line of work focuses on the role of nonverbal signals in creating social attitudes and biases among children and adults.

Sara E. Burke is an assistant professor in the Department of Psychology at Syracuse University. She received her $\mathrm{PhD}$ in social psychology from Yale University. Her research explores variations in the manifestations and consequences of prejudice targeting different social groups.

Rachel R. Hardeman is the Blue Cross Endowed Professor of Health and Racial Equity and Founding Director of the Center for Antiracism Research for Health Equity at the University Of Minnesota School Of Public Health. She received her PhD in health services research policy \& administration (sociology of health and illness focus) from the University of Minnesota. Dr. Hardeman's research is focused on understanding the multiple ways in which racism impacts health care delivery and health outcomes. Her primary line of research is centered on elucidating the impact of structural racism on maternal and infant health outcomes.

Sean M. Phelan is an associate professor of health services research at Mayo Clinic. He received his $\mathrm{PhD}$ in epidemiology (social/behavioral focus) from the University of Minnesota. His research is focused on understanding the implications of stigma for health care quality and outcomes as well as the organizational climate of healthcare organizations. 


\section{Acknowledgements}

Research reported in this publication was supported by the Eunice Kennedy Shriver National Institute of Child Health and Human Development of the National Institutes of Health under award number R21HD076603.

The authors would like to thank Michelle van Ryn and John Dovidio for feedback on earlier drafts of this manuscript and their contributions as Co-Investigators on NIH grant R21HD076603; Max Tiako for his feedback and insight on the "residency goal stability" outcome; and Deborah Finstad and Jamison Odiet for their help with the data collection and data management process. 


\begin{abstract}
Self-affirmation interventions have been shown to mitigate the negative psychological effects of stereotype threat on Black students in secondary and undergraduate education. However, there is currently limited research testing whether Black students in medical schools may also experience the negative influences of stereotype threat. Until now, it has been unclear whether Black (vs. White) students experience a lower sense of belonging in medical school and whether they can benefit from self-affirmation interventions during medical training. With a longitudinal field experiment, we tested (a) whether Black (vs. White) medical students in the US experience decrements in psychological well-being (i.e., fatigue, depression, anxiety), sense of belonging, perceived residency competitiveness, and residency goal stability; and (b) the extent to which a self-affirmation intervention would ameliorate any observed disparities in these outcomes for Black students. With a sample of 234 Black and 182 White medical students across 50 schools in the US, we found that Black students tended to report more fatigue and less belonging than White students; however, the self-affirmation intervention did not significantly influence students' fatigue, depression, anxiety, or belonging. Unexpectedly, Black students in the selfaffirmation (vs. control) condition reported lower perceived competitiveness for residency. White students' perceived competitiveness for residency was unaffected by the intervention. Exploratory analyses revealed that Black (vs. White) students were less likely to indicate stable residency goals over time, which may be an indication of threat; however this racial gap was eliminated with the intervention. We discuss the plausible reasons for these findings and provide recommendations for future work in this area.
\end{abstract}




\section{Testing a Self-Affirmation Intervention for Improving the Psychosocial Health of Black and White Medical Students in the US}

Black students often confront widely shared beliefs of lower competency in US educational settings (Steele, 1997; Steele et al., 2002). Such negative stereotypes may predispose Black students to a range of stressors that adversely affect their well-being and undermine their academic performance (Lewis \& Sekaquaptewa, 2016). However, when Black students are led to affirm their values and strengths, they can be buffered from some of the harm of racial stressors (Sherman \& Cohen, 2006; Steele, 1988). Self-affirmation interventions have been effective for Black students in many educational contexts (Cohen et al., 2006; Cohen et al., 2009; Cohen \& Sherman, 2014; Sherman \& Cohen, 2006), but they have yet to be tested in one important and understudied educational environment in the US: medical schools. Developing strategies to empower Black students to persist and succeed in medical school is vital to addressing the vast underrepresentation of Black medical providers in healthcare, with such underrepresentation potentially contributing to racial disparities in healthcare quality (Klonoff, 2009; Nelson, 2002; Smedley et al., 2004; Sullivan, 2004). The current work tests whether Black students in US medical schools suffer from lower well-being, feelings of belonging, self-efficacy, and goal stability than White students, and whether a self-affirmation intervention can close any such racial gaps.

\section{Racial Stressors in Medical School}

In educational contexts, like medical schools, Black students may face racial stereotypes regarding their intellectual abilities, which are inconsistent with academic success (Aronson et al., 1998; Steele, 1997; van Ryn \& Burke, 2000; van Ryn et al., 2006; van Ryn et al., 2011). Concerns about confirming these negative beliefs can reduce Black students' self-worth and 
yield harmful outcomes for their health, well-being, and performance (Spencer et al., 2016). Psychologists refer to this experience as stereotype threat, a stressful psychological state resulting from an awareness of a negative stereotype about one's social group and concern about confirming that stereotype (Spencer et al., 2016; Steele, 1997; Steele et al., 2002). Several studies have documented the negative effects of stereotype threat and racial stress on academic performance (Nguyen \& Ryan, 2008; Walton \& Spencer, 2009). These studies suggest that stereotype threat could be at play for several critical racial disparities among medical students that prevent sufficient Black representation among medical providers. For example, relative to their White peers, Black students are less likely to complete undergraduate degrees, tend to have lower performance on the Medical College Admission Test (MCAT), and, perhaps as a consequence, are less likely to be accepted into medical school (Education CoGM, 2005). Within their first year of medical school, Black students already report experiencing lower psychological well-being, greater stress, and lower feelings of acceptance than White medical students (Cressey, 2008; Hardeman et al., 2016; Nunez-Smith et al., 2009; Perry et al., 2016; Sanchez et al., 2011).

Black students in medical school experience racial stressors that can erode their sense of belonging, well-being, efficacy, and goal stability. For example, Black medical students report feeling more socially isolated, more discriminated against, greater tokenization, and greater perceived intellectual inferiority amid the vast numerical majority of their White peers and professors (Acheampong et al., 2019; Diaz et al., 2020; Liebshutz et al., 2006; Odom et al., 2007). Moreover, a qualitative study conducted with Black male medical students, revealed that they perceived attending physicians at their institution to view Black students as academically weaker than other students (Acheampong et al., 2019). These Black students also reported that 
race-related stressors negatively affected their physical health and emotional well-being, and felt that the institution was less likely to provide Black students with social and academic support. Consistent with this qualitative data, among a nationally representative sample of 3,659 fourthyear medical students, over $40 \%$ reported that they had observed faculty or attending physicians engaging in racially insensitive behavior, including making negative comments, disparaging remarks, or jokes about Black patients (Hardeman et al., 2017). Furthermore, the reporting of a hostile racial environment was negatively associated with the psychological well-being of all medical students (Hardeman et al., 2017). Because daily experiences with discrimination are depleting (e.g., Blair \& Steele, 2010; Gibbons et al., 2012; Richeson et al., 2005), racial stressors may diminish Black students' efficacy and willingness to take on challenges. Taken together, these findings suggest that Black students may often encounter information in the medical school environment signaling that their group is devalued, which may, in turn, negatively influence their sense of well-being, belonging, efficacy, and goal stability.

Black students' experiences with prejudice and discrimination may increase their attrition rates and undermine their competitiveness for residencies in several ways. Black students report that attending physicians have lower expectations for their academic success, and they in turn fear that they will unintentionally confirm these low expectations (Acheampong et al., 2019). Consistent with the idea that lowered expectations may stifle performance, relative to White students, Black students experience greater academic difficulties, receive lower grades, and receive lower medical licensing exam scores (American Association of Medical Colleges [AAMC], 2016; 2019; Edmond et al., 2001; Huff \& Fang, 1999; Mortensen et al., 2019; Tekian, 1998). Black medical students tend to underestimate their competitiveness for (and are less likely to pursue) highly selective residencies (Aagaard et al., 2005; Butler et al., 2008; Hardeman et al., 
2016; Jeffe et al., 2012; Nunez-Smith et al., 2009; Sanchez et al., 2011). Black medical students experience discrimination in other ways that are predictive of their residency prospects. For example, compared to their White colleagues, Black medical students were six times less likely to be selected for membership in Alpha Omega Alpha - a prominent medical school honor society — and $40 \%$ less likely to receive a high evaluation during their clinical training, both of which are associated with their competitiveness for highly selective residence specialties and career advancement (Boatright et al., 2017; Low et al., 2019; Wijesekera et al., 2019). Importantly, these findings held when the authors controlled for various demographic, educational, and other potentially confounding variables, indicating bias in the selection and grading processes that possibly undermines their residency prospects. Moreover, some medical professionals have suggested that competitive Black medical students may sometimes be “counseled out" of more competitive residencies (Campbell et al., 2018), which may decrease the stability of their residency goals over time. Taken together, Black medical students' experiences with discrimination and racial stressors may undermine their self-efficacy and perseverance with pursuing competitive residencies, thereby reducing the likelihood that they would apply for or be offered a competitive medical residency interview.

\section{Self-Affirmation Intervention}

People are motivated to maintain their self-integrity and worth as good and competent individuals (Sherman \& Cohen, 2006; Steele, 1988). Thus, when people are feeling devalued, this motivation may lead them to engage in protective strategies (e.g., defensive responding), such as distancing themselves from the threatening domain (e.g., medical school). Alternatively, people can bolster their self-integrity by affirming their values and strengths in another, personally important, domain that is not associated with the origin of the threat (e.g., family, 
profession, or religion; Easterbrook et al., 2021; Sherman \& Cohen, 2006). This process of affirming one's values or strengths is known as self-affirmation (Steele, 1988). Brief and lowcost interventions designed to affirm the self often involve participants indicating values that are personally important and writing about why those values matter to them (Easterbrook et al., 2021). A common comparison control condition instructs participants to select and write about values important to someone else.

Self-affirmation interventions are useful for protecting Black students from the deleterious effects of threatening educational contexts outside of medicine (e.g., Cohen et al., 2006; Cohen et al., 2009; Cohen \& Sherman, 2014; Easterbrook et al., 2021; Sherman \& Cohen, 2006). For example, in two field studies, Black students who were randomly assigned to selfaffirm (i.e., indicate their most important values and write an essay about those values) were less likely to perceive themselves in terms of racial stereotypes and performed better academically over the following two years than those who were not assigned to do a self-affirmation (Cohen et al., 2009). Brief self-affirmation interventions have also been shown to reduce the adverse effect of stereotype threat in other academic contexts, such as women's math and science performance (Johns et al., 2005; Miyake et al., 2010). For example, a values affirmation intervention has been found to close the gender gap by up to $89 \%$ in course grades for women in a graduate business school (Kinias \& Sim, 2016). In non-academic contexts, an affirmation intervention, meant to target Black patients' concerns that White healthcare providers might negatively stereotype them, improved communication between Black patients and White providers. Patients assigned to the intervention group exhibited less stress and were more responsive to the White healthcare provider relative to those in the control group (Havranek et al., 2012). 
Beyond improving performance, self-affirmation is associated with higher psychological well-being, in general, whether induced (Howell, 2017; Nelson et al., 2014) or spontaneously occurring (Emanuel et al., 2016). Moreover, self-affirmation interventions can buffer the health and well-being consequences of experiencing chronic stress, particularly among those who are most susceptible to or worried about threats to their self-integrity, such as Black students in educational contexts (see Cohen \& Sherman, 2014; Hadden et al., 2019). For example, selfaffirmed students approaching stressful midterm exams did not show an increase in the fight-orflight hormone epinephrine, whereas the non-affirmed students did (Sherman et al., 2009), suggesting that the intervention buffered the experience of stress on the physiological level. This stress-buffering effect was especially strong among students most concerned with appearing unlikable or incompetent. In another study, students who wrote about their daily experiences concerning their most important value (self-affirming) over a few weeks reported less stress and illness than the control group (Keough \& Markus, 1998). This effect was particularly strong among students who reported the largest number of daily obstacles to their self-worth (Keough \& Markus, 1998). Furthermore, one study showed that self-affirming can reduce the stress associated with attempting to lose weight, which ultimately resulted in better self-control and more achievement of weight-loss goals among self-affirmed (vs. non-affirmed) participants (Logel \& Cohen, 2012). This research suggests that a self-affirmation could buffer stress and enhance the well-being of Black medical students, specifically, because medical school is a context in which Black students disproportionately experience chronic stress due to stereotypes about their academic abilities.

There is also some initial evidence to suggest that self-affirming could enhance selfefficacy. A strong sense of self-efficacy_-beliefs about one's capabilities to produce desired 
effects - is a key ingredient of achievement (Bandura, 1977; 2010). Among medical students, perceived self-efficacy is an important indicator of performance and accomplishment (Mavis, 2001; Demirören et al., 2016). Given that self-affirming helps restore self-integrity in the face of threat, it makes sense that self-affirmation could increase self-efficacy when one's capability is being threatened (Easterbrook et al., 2021; Sherman \& Cohen, 2006; Steele, 1988). Indeed, selfaffirmation interventions have been found to enhance perceived self-efficacy in studies designed to increase the effectiveness of health messaging and the adoption of health-promoting behaviors (Epton et al., 2015; Sweeney \& Moyer, 2015). Moreover, self-affirmation interventions have been shown to improve self-control and facilitate resistance to cognitive depletion (Schmeichel \& Vohs, 2009). Taken together these studies suggest that self-affirmation could be useful for increasing self-efficacy among Black medical students, who may face racial stressors and threatening stereotypes of their competence and capability in academic institutions.

Although self-affirmation interventions of this kind have shown to be effective in a number of educational contexts (e.g., Easterbrook et al., 2021; Sherman et al., 2020), they are not always effective in reducing disparities. For instance, Protzko and Aronson (2016) observed evidence that when stigmatized individuals represent an exceptionally small minority group selfaffirmation interventions may not be effective. Critically, self-affirmation interventions have yet to be examined in the context of US medical schools. To our knowledge, only one published study has ever examined self-affirmation among medical school students--though it was conducted in a different cultural context, in the UK. Woolf et al. (2009) tested whether a brief self-affirmation intervention improved standardized testing and writing performance of White and ethnic minority—predominantly students who ethnically identify as South Asian (Indian, Pakistani, or Bangladeshi)—medical students in the UK. Their findings did not support the 
hypothesis that the intervention would narrow the ethnic performance gap. On the written assessment, the intervention had no effect on the writing performance of ethnic minority students relative to the control. On the standardized exam, both ethnic minority and White students in the intervention group performed better than those in the control condition. Given the different cultural context and participant demographics, it is unclear how these findings might apply to US medical schools. Moreover, Woolf and colleagues (2009) did not examine critical psychological factors associated with persistence and achievement, such as well-being, belonging, self-efficacy, and residency goal stability.

\section{Current Research}

Given the wide-ranging benefits that have been observed as a result of self-affirmation interventions (Easterbrook et al., 2021), it appears as though it may be an ideal approach for addressing challenges to psychological well-being, belonging, and self-efficacy (i.e., perceived residency competitiveness) faced by Black medical students. Building upon this prior evidence, the current work sought to extend the research on the racial stress of and self-affirmation interventions for Black medical students attending predominantly White institutions in the US. Using a longitudinal field experiment, we first investigated whether there are racial group differences among medical students in terms of their psychological well-being, sense of belonging, and self-efficacy regarding residency competitiveness. Second, we tested the extent to which a self-affirmation intervention would influence these outcomes in Black and White medical students. We tested the effectiveness of the intervention over three time-points during students' second year of medical school - a time when underrepresented minority students are most likely to report experiencing prejudice (Espaillat et al., 2019). Given the discussion in the literature over whether self-affirmation can enhance persistence with difficult goals (e.g., Cohen 
\& Sherman, 2014; Schmeichel \& Vohs, 2009; Sherman et al., 2020; Vohs et al., 2013), we explored whether Black and White medical students differed in the stability of their residency goals over time and whether any such differences were influenced by the intervention. This is the first known attempt to experimentally employ a self-affirmation intervention to attenuate the negative psychological effects Black students experience in US medical school settings.

We predicted that Black students would report decrements in psychosocial health, such that Black students would report lower well-being, belonging, than White students. This would be symptomatic of Black students experiencing stereotype threat and other racial stressors in medical school. We anticipated that Black students who were self-affirmed (vs. those in the control condition) would report increased well-being (i.e., decreased fatigue, depression, and anxiety), sense of belonging, and perceived residency competitiveness. The effect of selfaffirmation on stability of residency choice was also examined in an exploratory analysis.

We did not anticipate that the intervention would influence the outcomes of White students, given that they do not generally face negative racial stereotypes within academic contexts in the U.S. (e.g., Cohen et al., 2009; Sherman et al., 2020). We predicted that any observed racial differences in well-being, belonging, and perceived residency competitiveness at Wave 1 (the beginning of the second year of medical school) would be attenuated over the course of the academic year for Black students in the intervention condition.

\section{Method}

\section{Sample and Sampling Method}

The current study used a previously established sampling method from the Medical Student Cognitive Habits and Growth Evaluation Study (CHANGES; Phelan et al., 2014). The CHANGE study randomly selected 50 medical schools in the US from strata of public/private 
schools and six regions of the country with similar gender and race distributions to the population of all first-year medical students (American Association of Medical Colleges [AAMC] Matriculating Student Questionnaire [MSQ], 2016). We sampled a new cohort of students from the previously selected 50 medical schools. To contact the sample, we purchased contact information from the AAMC for 8,324 students--of which 5,715 (for whom email addresses were available) were contacted by email and the remaining 2,609 (whose email addresses were not available) were sent mail-outs. Consistent with the CHANGE study (see Perry et al., 2016), we anticipated that we would be able to obtain a sample of $\sim 50 \%$ of the 555 Black medical students from the 50 sampled schools. Thus, our targeted Black, second-year medical student sample size goal was $\sim 300$. Based on grant funding limitations, we targeted a sample size of 150 White second-year medical students; we aimed to oversample Black students to focus on the experiences of Black medical students. All of the 555 Black students enrolled in their second year at the targeted medical schools were contacted, and $42.2 \%$ of those students participated in our study. Our final sample $(N=416)$ included 234 Black and 182 White medical students ${ }^{1}$ who participated between September of 2014 and July of 2015. The majority of the participants were women (58\%) and heterosexual (92\%), and their ages ranged from 20 to 43 years $(M=25.21, S D=2.98)$. Students were compensated with $\$ 50$ for their participation at each wave of data collection ( $\$ 150$ total). For more details on sampling characteristics see Open Science Framework: https://osf.io/bhp3w/?view_only=e015c49d57074a58a71eb03dff943742

\section{Measures and Procedure}

\footnotetext{
${ }^{1}$ Because some White students started the survey but did not immediately complete it (allowing others to start the survey even though our quota had been met), our final sample included more White medical students than we intended to target.
} 
Using an experimental design, participants were randomly assigned to the selfaffirmation intervention group or the control group. During their second year of medical school, students received electronic surveys via Qualtrics at three time-points over one academic year-September 2014 (Wave 1, W1), January 2015 (Wave 2, W2, 90\% of original sample retained), and May 2015 (Wave 3, W3, 85\% of the original sample retained). At W1, students first completed baseline measures of psychological well-being, belonging, residency competitiveness, and residency goals, followed by the self-affirmation task; at W2, students first completed another measure of their psychological well-being, belonging, perceived residency competitiveness, and residency goals, followed by the self-affirmation task; finally, at W3, students completed the self-affirmation task and the final set of measures of their psychological well-being, belonging, residency self-efficacy, and residency goals. As with previous selfaffirmation work (Cohen et al., 2006; Cohen et al., 2009; Havranek et al., 2012; Johns et al., 2005; Miyake et al., 2010), participants were asked to read a list of values and rank them in order from "most important" to "least important." The values included the following: a sense of humor, religious values, relationships with friends or family, music, politics, membership in a community or social group, living in the moment, independence, creativity, artistic ability, and athletic ability. Participants in the experimental condition were then asked to write about why their highest-ranked value was important to them. Participants in the control condition received virtually identical instructions, except they were instructed to write about their least important value and why it might be important to "someone else."

Consistent with previous self-affirmation work (Cohen et al., 2009), participants were also asked to make a series of ratings on their value selections to further focus participants' engagement with the intervention. Participants in the experimental condition were asked to 
indicate their level of agreement with four items, including "This value has influenced my life," "In general, I try to live up to this value," "I care about this value," and "This value is an important part of who I am" on a 7-point scale, from 1 (strongly disagree) to 7 (strongly agree), Cronbach's alphas $=.90^{\mathrm{W} 1}, .87^{\mathrm{W} 2}, \& .93^{\mathrm{W} 3}$, respectively. Participants in the control condition answered the same questions focused on other people (e.g., "These values have influenced some other people.”). Because these ratings were merely part of the manipulation, we did not analyze these responses.

\section{Psychological Well-being, Belonging, Residency Self-efficacy, and Residency Goal Stability}

Psychological well-being was assessed using the Anxiety, Depression, and Fatigue PROMIS short forms (Cella et al., 2007), using response 5-point scales ranging from 1 (Never) to 5 (Always). Sample items include, "In the past month, how often did you feel tired?" (Fatigue scale, five items; Cronbach's alpha =.91), "In the past 7 days, I felt nervous" (Anxiety scale, seven items; Cronbach's alpha $=.93$ ), and "In the past 7 days, I felt sad" (Depression scale, eight items; Cronbach's alpha $=.94)$. The belonging measure was adapted from the Situational Belonging scale (Murphy et al., 2007, 5 items; Cronbach's alpha =.91). Sample items include, "How much do you feel like you belong in medical school?" on a 5-point scale, from 1 (not at all) to 5 (extremely). Perceived residency competitiveness was created and measured with the following single item: "Thinking about the future, how likely are you to be accepted into a top 10 residency?" on a 7-point scale, from 1 (very unlikely) to 7 (very likely). For the residency goal stability measure, students indicated which specific residency specialty they were intending to pursue. Residency goal options consisted of 25 choices, including anesthesiology, dermatology, family medicine, internal medicine, neurology, pediatrics, plastic surgery, and thoracic surgery). 
Because residency goals were measured at three different time-points, we could assess the degree to which students' residency goals were stable over the measurement period. Specifically, residency goal responses were recoded as stable or unstable from Waves 1 to 2 (and from Waves 2 to 3). If the student's choices remained the same from one wave to the next they were coded as stable $(0)$ and if they changed they were coded as unstable (1). The outcomes reported here were the primary variables of interest, though several additional measures were included for exploratory purposes. (See OSF for full measures list:

https://osf.io/bhp3w/?view_only=e015c49d57074a58a71eb03dff943742). Bivariate correlations between measures at each wave, broken down by race, are available in Tables 2-4.

To account for whether the academic competitiveness of the medical schools selected was predictive of participant outcomes, we included the school-level Medical College Admission Test (MCAT) scores and GPA of admitted students (collected from the CHANGE Study dataset (see Phelan et al., 2014 for more information about the CHANGE Study) in our analyses. We did not have access to participants' individual-level GPAs or MCAT scores.

\section{Participant Response Coding}

Two research assistants (a Black man and a White woman) were trained to content code participants' responses based on the following instructions, which were based on previous research (Borman et al., 2018). Participants' responses were coded as affirming the self if they (1) mentioned one of the specified values in their response and (2) affirmed that value by discussing why it is personally important to them (e.g., using "like," "love," "care about," "good at," "best at"). Responses of participants meeting both criteria were coded as affirming the self; all other responses were coded as not affirming the self. The two research assistants coded a 
subset of 20 responses from each wave (60 total), which were checked by the lead author and all discrepancies were corrected. These two coders then went on to code all of the responses, showing high interrater reliability, Kappa $=0.908(p<.001), 95 \%$ CI $[0.907,0.910]$. All remaining discrepancies were checked and resolved by the lead authors. At each wave, the vast majority of the participants in the self-affirmation condition consistently self-affirmed $\left(84 \%{ }^{\mathrm{W} 1}\right.$, $86 \%{ }^{\mathrm{W} 2}, 81 \%{ }^{\mathrm{W} 3}$ ), whereas very few of the participants in the control condition self-affirmed $\left(0 \% \mathrm{~W} 1,1 \%{ }^{\mathrm{W} 2}, 1 \%{ }^{\mathrm{W} 3}\right)$. Self-affirmations across waves were summed to create a new variable (self-affirmation frequency) indexing self-affirmation (scores range from 0 to 3 ), with higher scores indicating more self-affirmation across waves.

\section{Results}

To test the effect of the intervention on measures of psychological well-being (fatigue, depression, and anxiety), belonging, and perceived residency competitiveness, we used mixedeffects models, nesting students within institutions (random intercepts for students by the institution), using the PROC MIXED function in SAS. To ensure that our models were robust against violations of assumptions we utilized the "empirical" statement in SAS to request robust estimates. Effect size calculations were done using Edwards et al. (2008) formula for calculating $R 2$ in linear mixed models. The wave of data collection was included in the model as a categorical predictor (rather than a continuous predictor) to allow for the possibility that changes across waves were non-linear. Student race $(0=$ White, $1=$ Black $)$, intervention group $(0=$ control, $1=$ intervention), and the wave of data collection $(\mathrm{W} 1=-1, \mathrm{~W} 2=0, \mathrm{~W} 3=1)$ were included as interacting predictors in all models, and fixed effects of median MCAT score and 
GPA of admitted students (at the institution level) were included in the models as statistical controls. This is followed by a second set of models in which the "intervention group" independent variable was replaced with the coded "self-affirmation frequency" variable. We used a Bonferroni-correction $(\alpha=.025)$ to account for the fact that we conducted these two separate analyses for each outcome.

\section{Psychological Well-being}

We anticipated that Black students would report lower psychological well-being across all measured indicators (i.e., fatigue, anxiety, and depression) and that — among Black students only - the self-affirmation intervention would decrease self-reported fatigue, anxiety, and depression relative to the control.

\section{Fatigue}

The effect of student race on fatigue fell above our Bonferroni-corrected alpha level $(\alpha=$ .025), though we provide an interpretation of this nearly significant effect for full transparency. Black students reported more fatigue $(M=2.89, S E=0.05)$ than White students $(M=2.74, S E=$ $0.05), F(1,719)=4.08, p=.044, R^{2}=.005$. The main effect of intervention group was nonsignificant, students in the control group did not reported more fatigue $(M=2.85, S E=0.05)$ than students in the intervention group $(M=2.79, S E=0.05), F(1,719)=0.67, p=.414$. The main effect of wave in which data were collected was non-significant, students reported roughly equivalent levels of fatigue at W1 $(M=2.82, S E=0.04)$, W2 $(M=2.79, S E=0.04)$, and W3 $(M$ $=2.84, S E=0.04), F(2,719)=0.91, p=.402$. The interaction between student race and 
intervention group was not statistically significant, $F(1,719)=0.32, p=.574$. The interaction between student race and wave of data collection also was not statistically significant, $F(2,719)$ $=0.85, p=.429$, nor was the interaction between wave of data collection and intervention group, $F(2,719)=0.29, p=.751$. Furthermore, the three-way interaction between student race, wave of data collection, and intervention group was not statistically significant, $F(2,719)=0.13, p=$ 875. As university median MCAT score increased, fatigue decreased $(b=-0.05, S E=0.02)$, $t(719)=-2.59, p=.010, R^{2}=.009$. Median GPA of admitted students did not significantly predict fatigue $(b=0.40, S E=0.66), t(719)=0.61, p=.544$.

\section{Anxiety}

Black students did not report more anxiety $(M=2.64, S E=0.05)$ than White students $(M$ $=2.66, S E=0.05), F(1,719)=0.14, p=.709$. The main effect of intervention group was nonsignificant, students in the control group did not reported more anxiety $(M=2.66, S E=0.04)$ than students in the intervention group $(M=2.64, S E=0.05), F(1,719)=0.12, p=.728$. The wave in which data were collected predicted self-reported anxiety, $F(2,719)=5.20, p=.006, R^{2}$ $=.014$. Students reported more anxiety at $\mathrm{W} 3(M=2.73, S E=0.04)$ than at $\mathrm{W} 1(M=2.62, S E=$ $0.04 ; t=-2.96, p=.003)$ and $\mathrm{W} 2(M=2.62, S E=0.04 ; t=-2.78, p=.006)$. The interaction between student race and intervention group was not statistically significant, $F(1,719)=2.30, p$ $=.130$. The interaction between student race and wave of data collection also was not statistically significant, $F(2,719)=0.33, p=.722$, nor was the interaction between wave of data collection and intervention group, $F(2,719)=0.50, p=.609$. Furthermore, the three-way 
interaction between student race, wave of data collection, and intervention group was not statistically significant, $F(2,719)=0.77, p=.461$. As university median MCAT score increased, anxiety decreased $(b=-0.04, S E=0.02), t(719)=-2.36, p=.018, R^{2}=.008$. Median GPA of admitted students did not significantly predict anxiety $(b=0.67, S E=0.56), t(719)=1.20, p=$ .231 .

\section{Depression}

Black students did not report more depression $(M=1.82, S E=0.04)$ than White students $(M=1.75, S E=0.04), F(1,719)=1.03, p=.310$. The main effect of intervention group was non-significant--students in the control group did not report more depression $(M=1.80, S E=$ $0.04)$ than students in the intervention group $(M=1.79, S E=0.04), F(1,719)=0.02, p=.883$. The effect of wave on self-reported depression did not reach our Bonferroni-corrected alpha level, $F(2,719)=2.80, p=.061, R^{2}=.008$. However, because this effect was nearly significant we conducted Bonferroni corrected follow-up comparisons between waves. Students reported more depression at W2 $(M=1.82, S E=0.04)$ than at $\mathrm{W} 1(M=1.75, S E=0.04), t(719)=-2.28$, $p=.023$. Depression did not significantly differ from W2 to W3 $(M=1.80, S E=0.04), \mathrm{t}(719)=$ $0.48, p=1.00$. The interaction between student race and intervention group was not statistically significant, $F(1,719)=0.73, p=.395$. The interaction between student race and wave of data collection also was not statistically significant, $F(2,719)=0.92, p=.398$, nor was the interaction between wave of data collection and intervention group, $F(2,719)=0.12, p=.883$. Furthermore, the three-way interaction between student race, wave of data collection, and intervention group 
was not statistically significant, $F(2,719)=0.64, p=.525$. Median MCAT score of admitted students did not significantly predict depression $(b=-0.02, S E=0.02), t(719)=-1.24, p=.215$. Median GPA of admitted students did not significantly predict depression $(b=0.08, S E=0.57)$, $t(719)=0.15, p=.884$

\section{Belonging}

We predicted that Black students would report a lower sense of belonging, on average, than White students. Student race was a statistically significant predictor of self-reported belonging, with White students (overall, across all waves) reporting greater belonging $(M=3.78$, $S E=0.05)$ than Black students $(M=3.58, S E=0.05), F(1,719)=8.17, p=.004, R^{2}=.011$. The main effect of intervention group was non-significant, students in the control group did not reported lower feelings of belonging $(M=2.68, S E=0.05)$ than students in the intervention group $(M=2.68, S E=0.05), F(1,719)=0.02, p=.899$. We did find that wave of data collection predicted belonging, $F(2,719)=3.94, p=.020, \mathrm{R} 2=.011$. Bonferroni-corrected pairwise comparisons indicated that students reported more belonging at $\mathrm{W} 1(M=3.72, S E=0.04)$ than at $\mathrm{W} 3(M=3.64, S E=0.04), t(719)=2.81, p=.016$. Belonging at $\mathrm{W} 2(M=3.68, S E=0.04) \mathrm{did}$ not significantly differ from $\mathrm{W} 1, t(719)=1.53, p=.377$, or $\mathrm{W} 3, t(719)=1.52, p=.383$.

The interaction between student race and intervention group was not statistically significant, $F(1,719)=0.06, p=.813$. The interaction between student race and wave of data collection also was not statistically significant, $F(2,719)=1.12, p=.327$, nor was the interaction between wave of data collection and intervention group, $F(2,719)=0.36, p=.699$. The three- 
way interaction between student race, intervention, and wave was statistically significant, $F(2$, $719)=3.72, p=.025, R^{2}=.010($ see Table 1$)$. However, the intervention and control condition participants did not significantly differ from one another among White students or Black students at any of the three waves $(p s>.300)$.

Median MCAT score of admitted students did not significantly predict belonging $(b=$ $0.00, S E=0.02), t(719)=0.04, p=.964$. Median GPA of admitted students did not significantly predict depression $(b=-0.31, S E=0.63), t(719)=-0.49, p=.621$.

Table 1

Mean Belonging at Each Wave Broken Down By Race and Intervention Group

\begin{tabular}{ccccc}
\hline & \multicolumn{2}{c}{ Black Participants } & \multicolumn{2}{c}{ White Participants } \\
\hline Intervention & Control & Intervention & Control \\
\hline Wave 1 & $3.62(.07)_{\mathrm{a}}$ & $3.58(.07)_{\mathrm{a}}$ & $3.81(.08)_{\mathrm{b}}$ & $3.88(.07)_{\mathrm{b}}$ \\
Wave 2 & $3.57(.08)_{\mathrm{a}}$ & $3.63(.08)_{\mathrm{ab}}$ & $3.82(.09)_{\mathrm{b}}$ & $3.70(.08)_{\mathrm{ab}}$ \\
Wave 3 & $3.54(.09)_{\mathrm{ab}}$ & $3.54(.08)_{\mathrm{a}}$ & $3.76(.08)_{\mathrm{b}}$ & $3.73(.08)_{\mathrm{ab}}$ \\
\hline
\end{tabular}

Note. Standard errors are in parentheses. Differing subscripts for means in the same row indicate that means significantly differ $(p<.05)$.

\section{Perceived Residency Competitiveness}

We anticipated that Black students would perceive themselves to be less competitive for residency than White students, yet our findings indicated that Black students $(M=4.23, S E=$ $0.08)$ did not significantly differ from White students $(M=4.13, S E=0.09)$ in terms of perceived residency competitiveness, $\mathrm{F}(1,719)=0.76, p=.383$. The main effect of intervention group was non-significant--students in the control group did not reported less perceived residency 
competitiveness $(M=4.24, S E=0.08)$ than students in the intervention group $(M=4.13, S E=$ $0.08), F(1,719)=1.01, p=.315$. Wave of data collection significantly predicted perceived residency competitiveness, $F(2,719)=6.77, p=.001, R^{2}=.018$. The decrease in perceived medical residency competitiveness from W1 $(M=4.30, S E=0.06)$ to $\mathrm{W} 2(M=4.19, S E=0.07$; $p=.043$ ) did not reach our Bonferroni-corrected alpha level, however the decrease from W2 to W3 $(M=4.06, S E=0.07 ; p=.022)$ was statistically significant.

We also predicted that Black students in the self-affirmation group would perceive themselves to be more competitive for a selective medical residency than Black students in the control condition. Consistent with this, the interaction between student race and intervention group significantly predicted perceived residency competitiveness, $F(1,719)=5.60, p=.018$, $\mathrm{R} 2=.008$ (see Figure 1). But, overall (wave invariant), Black students in the control condition perceived themselves to be more competitive for residency placement $(M=4.43, S E=0.10)$ than Black students in the intervention condition $(M=4.04, S E=0.12), t(719)=2.50, p=.013$. White students did not differ in perceived residency competitiveness as a function of being in the control group $(M=4.05, S E=0.13)$ or the intervention group $(M=4.21, S E=0.11), t(400)=$ $0.92, p=.359$.

The interaction between student race and wave of data collection also was not statistically significant, $F(2,719)=0.25, p=.780$, nor was the interaction between wave of data collection and intervention group, $F(2,719)=0.73, p=.482$. Furthermore, the three-way interaction between student race, wave of data collection, and intervention group was not statistically 
significant, $F(2,719)=0.60, p=.547$. The fact that this pattern was wave invariant (i.e., seemed to be present even before the intervention), suggests that randomization of Black participants may have failed.

Median university MCAT score significantly predicted perceived residency competitiveness - as average MCAT score increased, students perceived themselves to be more competitive for residency, $(b=0.14, S E=0.03), t(719)=4.74, p<.001, R^{2}=.030$. Median GPA of admitted students did not significantly predict perceived residency competitiveness $(b=$ $0.78, S E=0.98), t(719)=0.80, p=.425$.

\section{Figure 1}

Perceived Residency Competitiveness by Student Race and Intervention Condition

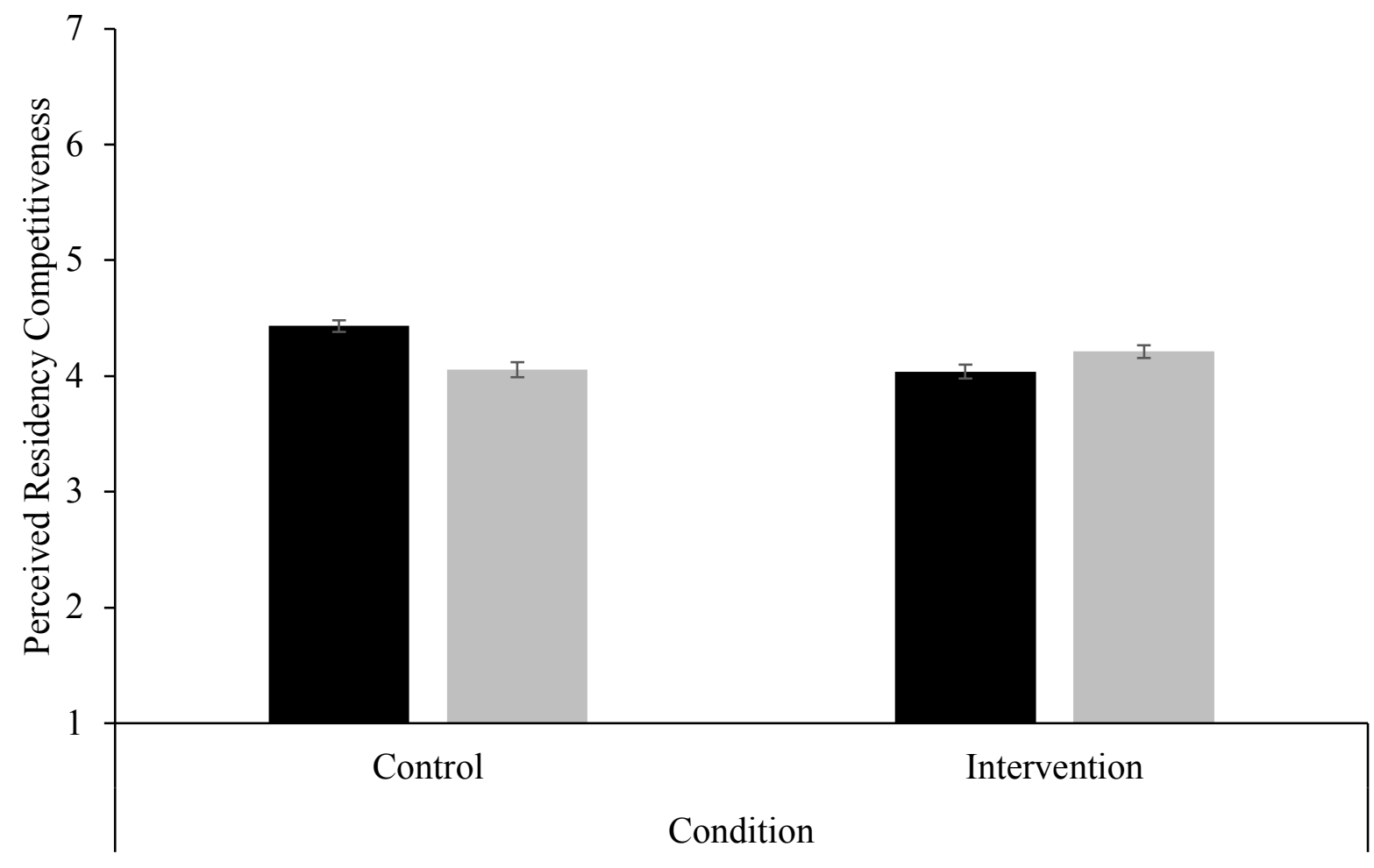

- Black Students $\square$ White Students 
Note. Perceived residency competitiveness was measured on a 1 (very unlikely) to 7 (very likely) scale, and error bars represent standard errors. Intervention and control significantly differed among Black students but not White students.

\section{Table 2}

Wave 1 Correlations and Descriptive Statistics Segmented by Student Race

\begin{tabular}{lccccccc}
\hline Wave 1 Variables & $M(S D)$ & 1 & 2 & 3 & 4 & 5 & 6 \\
\hline \multicolumn{1}{c}{$M(S D)$} & & 0.51 & 2.73 & 2.64 & 1.74 & 3.83 & 4.24 \\
& & $(0.50)$ & $(0.79)$ & $(0.69)$ & $(0.69)$ & $(0.71)$ & $(1.35)$ \\
1. Intervention $=1$, & 0.46 & & .02 & -.08 & -.03 & -.07 & .08 \\
$\quad$ Control =0 & $(0.50)$ & & $(.747)$ & $(.285)$ & $(.702)$ & $(.357)$ & $(.298)$ \\
2. Fatigue & 2.92 & -.05 & & $.53^{* * *}$ & $.45^{* * *}$ & $-.34 * * *$ & $-.21^{* *}$ \\
& $(0.89)$ & $(.419)$ & & $(<.001)$ & $(<.001)$ & $(<.001)$ & $(.004)$ \\
3. Anxiety & 2.58 & .02 & $.49^{* * *}$ & & $.61^{* * *}$ & $-.43^{* * *}$ & $-.22^{* *}$ \\
& $(0.82)$ & $(.776)$ & $(<.001)$ & & $(<.001)$ & $(<.001)$ & $(.002)$ \\
4. Depression & 1.75 & .01 & $.46^{* * *}$ & $.62^{* * *}$ & & $-.55^{* * *}$ & $-.29 * * *$ \\
& $(0.76)$ & $(.911)$ & $(<.001)$ & $(<.001)$ & & $(<.001)$ & $(<.001)$ \\
5. Belonging & 3.60 & .02 & $-.28^{* * *}$ & $-.36^{* * *}$ & $-.52^{* * *}$ & & $.26^{* * *}$ \\
& $(0.80)$ & $(.768)$ & $(<.001)$ & $(<.001)$ & $(<.001)$ & & $(<.001)$ \\
6. Residency & 4.38 & -.08 & -.08 & -.12 & $-.14 *$ & $.26 * * *$ & \\
Competitiveness & $(1.25)$ & $(.200)$ & $(.242)$ & $(.060)$ & $(.029)$ & $(<.001)$ & \\
\hline
\end{tabular}

Note. Pearson's r correlation coefficients (corresponding $p$ values) and descriptive statistics for

Wave 1 variables broken down by student race: Black students $(N=235$; below the diagonal) and White students $(N=184$; above the diagonal).

${ }^{*} p<.05,{ }^{* *} p<.01,{ }^{* * *} p<.001$

\section{Table 3}

Wave 2 Correlations and Descriptive Statistics Segmented by Student Race 


\begin{tabular}{lccccccc}
\hline Wave 2 Variables & $M(S D)$ & 1 & 2 & 3 & 4 & 5 & 6 \\
\hline \multicolumn{1}{c}{$M(S D)$} & & 0.51 & 2.73 & 2.64 & 1.81 & 3.74 & 4.09 \\
& & $(0.50)$ & $(0.82)$ & $(0.71)$ & $(0.72)$ & $(0.80)$ & $(1.44)$ \\
1. Intervention $=1$, & 0.46 & & .01 & -.09 & -.07 & .05 & .07 \\
Control $=0$ & $(0.50)$ & & $(.894)$ & $(.250)$ & $(.361)$ & $(.477)$ & $(.381)$ \\
2. Fatigue & 2.83 & -.02 & & $.49 * * *$ & $.43 * * *$ & $-.33 * * *$ & -.11 \\
& $(0.86)$ & $(.419)$ & & $(<.001)$ & $(<.001)$ & $(<.001)$ & $(.141)$ \\
3. Anxiety & 2.61 & .13 & $.47 * * *$ & & $.62 * * *$ & $-.36 * * *$ & $-.16^{*}$ \\
& $(0.80)$ & $(.067)$ & $(<.001)$ & & $(<.001)$ & $(<.001)$ & $(.017)$ \\
4. Depression & 1.86 & .08 & $.47 * * *$ & $.69 * * *$ & & $-.52 * * *$ & -.14 \\
& $(0.73)$ & $(.280)$ & $(<.001)$ & $(<.001)$ & & $(<.001)$ & $(.067)$ \\
5. Belonging & 3.60 & -.05 & $-.31 * * *$ & $-.53 * * *$ & $-.57 * * *$ & & $.19 *$ \\
6. Residency & $(0.82)$ & $(.444)$ & $(<.001)$ & $(<.001)$ & $(<.001)$ & & $(.010)$ \\
Competitiveness & $(1.37)$ & $(.020)$ & $(.005)$ & $(.004)$ & $(.003)$ & $(<.001)$ & \\
\hline
\end{tabular}

Note. Pearson's r correlation coefficients (corresponding $p$ values) and descriptive statistics for

Wave 2 variables broken down by student race: Black students $(N=199$; below the diagonal) and White students $(N=179$; above the diagonal).

$* p<.05, * * p<.01, * * * p<.001$

\section{Table 4}

Wave 3 Correlations and Descriptive Statistics Segmented by Student Race

\begin{tabular}{lccccccc}
\hline Wave 3 Variables & $M(S D)$ & 1 & 2 & 3 & 4 & 5 & 6 \\
\hline \multicolumn{1}{c}{$M(S D)$} & & 0.51 & 2.78 & 2.73 & 1.75 & 3.73 & 4.02 \\
& & $(0.50)$ & $(0.84)$ & $(0.79)$ & $(0.68)$ & $(0.75)$ & $(1.46)$ \\
1. Intervention =1, & 0.46 & & -.05 & -.06 & .01 & -.02 & .04 \\
$\quad$ Control =0 & $(0.50)$ & & $(.555)$ & $(.447)$ & $(.966)$ & $(.825)$ & $(.606)$ \\
& 2.85 & -.04 & & $.60 * * *$ & $.55^{* * *}$ & $-.44 * * *$ & -.12 \\
2. Fatigue & $(0.90)$ & $(.594)$ & & $(<.001)$ & $(<.001)$ & $(<.001)$ & $(.112)$ \\
& 2.74 & .03 & $.45^{* * *}$ & & $.65 * * *$ & $-.37 * * *$ & $-.16 *$ \\
3. Anxiety & $(0.88)$ & $(.684)$ & $(<.001)$ & & $(<.001)$ & $(<.001)$ & $(.036)$
\end{tabular}




$\begin{array}{lcccccccc}\text { 4. Depression } & 1.87 & .03 & .41^{* * *} & .67 * * * & & -.48^{* * *} & -.13 \\ & (0.83) & (.647) & (<.001) & (<.001) & & (<.001) & (.091) \\ \text { 5. Belonging } & 3.54 & -.01 & -.30^{* * *} & -.40^{* * *} & -.55^{* * *} & & .09 \\ & (0.85) & (.852) & (<.001) & (<.001) & (<.001) & & (.244) \\ \text { 6. Residency } & 4.10 & -.16^{*} & -.03 & -.17^{*} & -.24 * * & .32 * * * & \\ & \text { Competitiveness } & (1.44) & (.029) & (.721) & (.019) & (.001) & (<.001) & \end{array}$

Note. Pearson's r correlation coefficients (corresponding $p$ values) and descriptive statistics for

Wave 3 variables broken down by student race: Black students $(N=182$; below the diagonal) and White students $(N=173$; above the diagonal).

${ }^{*} p<.05,{ }^{* *} p<.01,{ }^{* * *} p<.001$

\section{Residency Goal Stability}

As an exploratory question, we tested the effect of the intervention on likelihood of residency goal stability. To do this we used a mixed-effects logistic model, nesting students within institutions (random intercepts for students by the institution), using the PROC GLIMMIX function in SAS. To ensure that our models were robust against violations of assumptions we utilized the "empirical" statement in SAS to request robust estimates. Student race $(0=$ White, $1=$ Black $)$ and intervention group $(0=$ control, $1=$ intervention $)$ were included as interacting predictors in all models. In these analyses, we could only use data from Wave 2 and Wave 3, because we were tracking changes in residency goals. We therefore included as control variables whether the change score was measured at Wave 2 (change from Wave 1 to Wave 2) or at Wave 3 (change from Wave 2 to Wave 3; W1-W2 =0, W2-W3 = 1), median MCAT score, and GPA of admitted students (at the institution level)

The effect of student race on likelihood of changing residency goals was statistically significant, such that Black students were more likely to report changed residency goals $($ probability $=.41, S E=.05)$ than White students (probability $=.19, S E=.04), F(1,414)=15.47$, 
$p<.001, O R=1.73$. The main effect of intervention group was non-significant, such that students in the control group were not more likely to report changed residency goals (probability $=.30, S E=.04)$ than students in the intervention group (probability $=.27, S E=.04), F(1,414)=$ $0.28, p=.598$. However, the interaction between student race and intervention group was statistically significant, $F(1,414)=4.15, p=.042$. Bonferroni-corrected pairwise comparisons indicated that Black students in the control condition were not significantly more likely to report changed residency goals (probability $=.49, S E=.05$ ) than Black students in the intervention condition $($ probability $=.33, S E=.05), t(414)=1.89, p=.355$. White students also did not differ in changes in residency goals as a function of being in the control group (probability $=.16, S E=$ .04 ) or the intervention group (probability $=.22, S E=.05), t(414)=-1.05, p=1.00$. However, when comparing students within condition, we saw that, in the control condition, Black students were more likely to report changed residency goals than White students, $t(414)=4.32, p<.001$. In contrast, in the intervention condition, Black students were not more likely to report changed residency goals than White students, $t(414)=1.45, p=.889$. This pattern of results suggests that the observed racial difference in changing residency goals (wherein Black students tended to change their goals more than White students), was mitigated as a function of the affirmation intervention.

The main effect of time-point was also significant, students became more likely to report changed residency goals over time $(b=0.37, S E=0.17), t(414)=2.18, p=.030, O R=1.45$. University median MCAT score was unrelated to likelihood of reporting changed residency goals $(b=-0.03, S E=0.07), t(414)=-0.39, p=.694$. Median GPA of admitted students did not significantly predict changes in residency goals $(b=-0.53, S E=2.31), t(414)=-0.23, p=.821$.

\section{Figure 2}




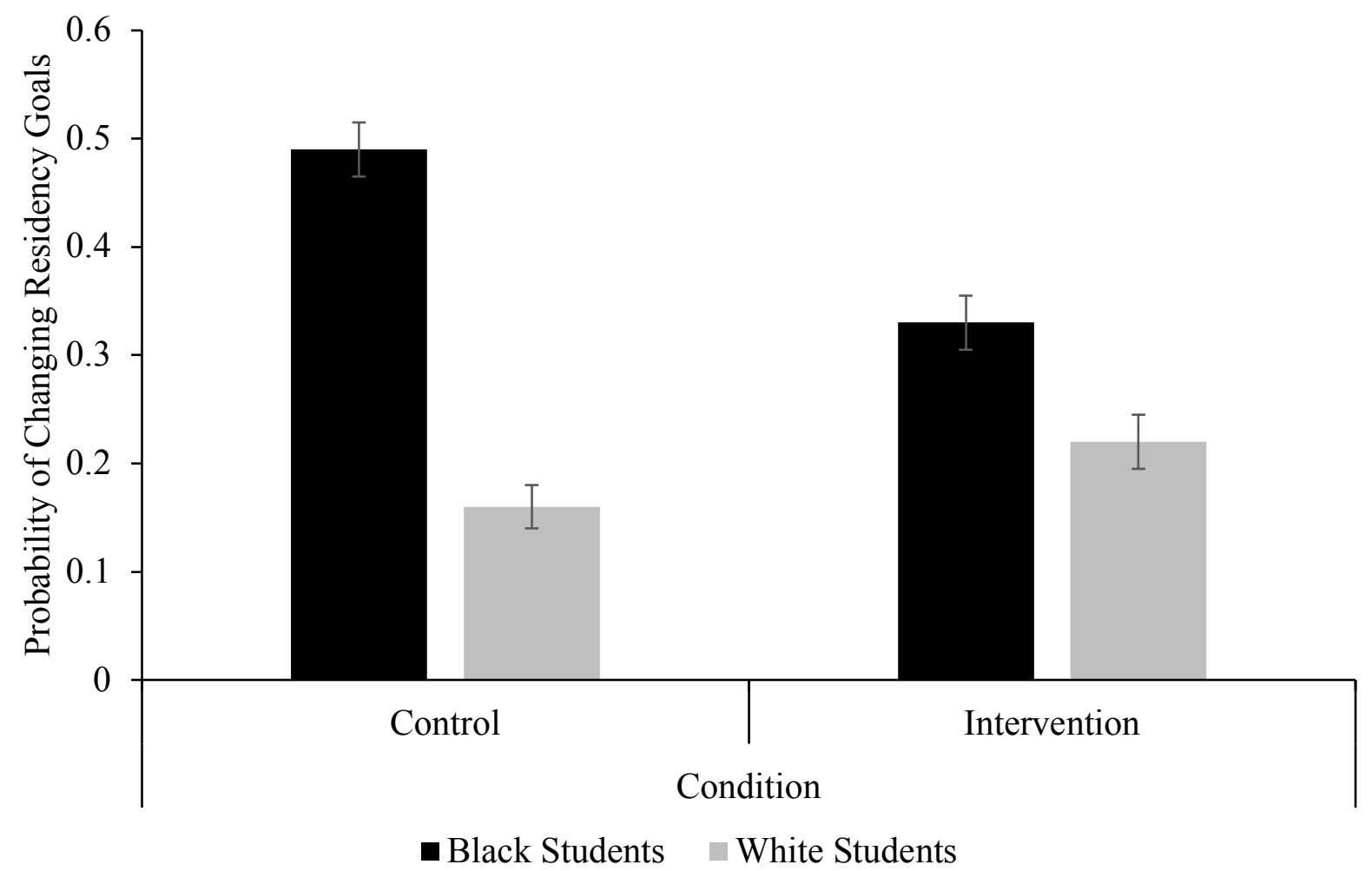

Note. Figure depicts estimated probability of residency goal change collapsed across wave changes. Error bars indicate standard errors.

\section{Analyses of Coded Self-Affirmation Frequency}

\section{Psychological Well-being}

To examine whether frequency of self-affirmation affected our outcomes of interest, we replicated our previous mixed-effects models (described on p. 16), replacing the condition variable with the coded measure of the frequency of self-affirmation. We predicted that among Black students the self-affirmation would decrease self-reported fatigue, anxiety, and depression. 
Fatigue. In this model, Black students reported fatigue $(M=2.89, S E=0.05)$ did not significantly differ from that of White students $(M=2.74, S E=0.05), F(1,719)=1.61, p=.205$. The main effect of frequency of self-affirmation was non-significant $(b=-0.01, S E=0.04)$, $t(719)=-0.29, p=.770$. The main effect of wave in which data were collected was nonsignificant, students reported roughly equivalent levels of fatigue at $\mathrm{W} 1(M=2.82, S E=0.04)$, $\mathrm{W} 2(M=2.79, S E=0.04)$, and W3 $(M=2.84, S E=0.04), F(2,719)=0.68, p=.508$. The interaction between student race and frequency of self-affirmation was not statistically significant, $F(1,719)=0.16, p=.693$. The interaction between student race and wave of data collection also was not statistically significant, $F(2,719)=0.82, p=.441$, nor was the interaction between wave of data collection and intervention group, $F(2,719)=0.04, p=.957$. Furthermore, the three-way interaction between student race, wave of data collection, and frequency of selfaffirmation was not statistically significant, $F(2,719)=0.13, p=.876$. As university median MCAT score increased, fatigue decreased $(b=-0.05, S E=0.02), t(719)=-2.64, p=.008$. Median GPA of admitted students did not significantly predict fatigue $(b=0.44, S E=0.65)$, $t(719)=0.67, p=.502$.

Anxiety. The main effect of student race (Black students: $M=2.64, S E=0.05$; White students: $M=2.67, S E=0.04$ ) on anxiety did not reach our Bonferroni-corrected alpha level, $F(1,719)=2.99, p=.084$. The main effect of frequency of self-affirmation did not reach our Bonferroni-corrected alpha level, however it trended toward more affirmation predicting increased anxiety $(b=0.09, S E=0.04), t(719)=2.03, p=.042$. The wave in which data were 
collected predicted self-reported anxiety, $F(2,719)=3.76, p=.024, R^{2}=.010$. Students reported more anxiety at $\mathrm{W} 3(M=2.73, S E=0.04)$ than at $\mathrm{W} 1(M=2.62, S E=0.04 ; t=-2.93, p=.004)$ and W2 $(M=2.62, S E=0.04 ; t=-2.83, p=.005)$. The interaction between student race and frequency of self-affirmation did not reach our Bonferroni-corrected alpha level, $F(1,719)=$ $3.79, p=.052, R^{2}=.005$. Because this interaction was nearly significant we followed-up by examining simple slopes, but frequency of self-affirmation did not significantly predict anxiety among Black students $(b=0.06, S E=0.04, t(719)=1.62, p=.106)$ or White students $(b=-$ $0.04, S E=0.03, t(719)=-1.11, p=.268)$.

The interaction between student race and wave of data collection also was not statistically significant, $F(2,719)=0.72, p=.490$, nor was the interaction between wave of data collection and intervention group, $F(2,719)=0.15, p=.860$. Furthermore, the three-way interaction between student race, wave of data collection, and intervention group was not statistically significant, $F(2,719)=0.66, p=.516$. As university median MCAT score increased, anxiety decreased $(b=-0.04, S E=0.02), t(719)=-2.38, p=.018, R^{2}=.008$. Median GPA of admitted students did not significantly predict anxiety $(b=0.67, S E=0.56), t(719)=1.20, p=.231$.

Depression. Black students did not report more depression $(M=1.82, S E=0.04)$ than White students $(M=1.76, S E=0.04), F(1,719)=0.04, p=.840$. The main effect of frequency of self-affirmation was non-significant $(b=0.05, S E=0.04), t(719)=1.36, p=.176$. The effect of wave on self-reported depression was not statistically significant, $F(2,719)=1.60, p=.204$. The interaction between student race and frequency of self-affirmation was not statistically 
significant, $F(1,719)=1.99, p=.159$. The interaction between student race and wave of data collection also was not statistically significant, $F(2,719)=0.78, p=.458$, nor was the interaction between wave of data collection and intervention group, $F(2,719)=0.34, p=.710$. Furthermore, the three-way interaction between student race, wave of data collection, and frequency of selfaffirmation was not statistically significant, $F(2,719)=0.24, p=.788$. Median MCAT score of admitted students did not significantly predict depression $(b=-0.02, S E=0.02), t(719)=-1.25$, $p=.211$. Median GPA of admitted students did not significantly predict depression $(b=0.08, S E$ $=0.57), t(719)=0.14, p=.892$.

\section{Belonging}

The effect of student race on self-reported belonging did not reach our Bonferronicorrected alpha level in this model, thus belonging for White students $(M=3.76, S E=0.07)$ and Black students $(M=3.60, S E=0.06)$ did not significantly differ, $F(1,719)=2.87, p=.091$. The main effect of frequency of self-affirmation on belonging was non-significant $(b=-0.04, S E=$ $0.04), t(719)=-0.85, p=.394$. The effect of wave on feelings of belonging did not reach our Bonferroni-corrected alpha level, $F(2,719)=3.07, p=.047$. However, because this effect was nearly significant we conducted follow-up comparisons between waves. Bonferroni-corrected pairwise comparisons indicated that students reported more belonging at $\mathrm{W} 1(M=3.73, S E=$ $0.05)$ than at $\mathrm{W} 3(M=3.63, S E=0.05), t(719)=2.48, p=.040$. Belonging at $\mathrm{W} 2(M=3.67, S E$ $=0.05)$ did not significantly differ from $\mathrm{W} 1, t(719)=1.47, p=.425$, or $\mathrm{W} 3, t(719)=-1.02, p=$ .931. 
Although we anticipated that frequency of self-affirmation would increase a sense of belonging among Black students, the frequency of self-affirmation did not significantly interact with student race, $F(1,719)=0.51, p=.476$. The interaction between student race and wave of data collection did not reach our Bonferroni-corrected alpha level, $F(2,719)=3.66, p=.026, R^{2}$ $=.010$. However, because this effect was nearly significant we conducted Bonferroni-corrected follow-up comparisons between students at each wave. At W1 the difference between White students $(M=3.86, S E=0.07)$ and Black students $(M=3.59, S E=0.07)$ failed to meet our alpha level, $t(719)=2.83, p=.072$. At W2 the difference between White students $(M=3.70, S E=$ $0.08)$ and Black students $(M=3.64, S E=0.07)$ was not statistically significant, $t(719)=0.51, p$ $=1.00$. At W3 the difference between White students $(M=3.71, S E=0.07)$ and Black students $(M=3.56, S E=0.07)$ was not statistically significant, $t(719)=1.39, p=1.00$. The interaction between wave of data collection and frequency of self-affirmation was not statistically significant, $F(2,719)=0.24, p=.789$. The three-way interaction between student race, affirmation frequency, and wave did not reach our Bonferroni-corrected alpha level, $F(2,719)=$ $3.56, p=.029, R^{2}=.010$. Because this interaction was nearly significant we conducted follow-up tests, but the simple slopes for frequency of self-affirmation were not significant for White students (W1: $b=-0.02, S E=0.04, p=.693 ; \mathrm{W} 2: b=0.03, S E=0.04, p=.447 ; \mathrm{W} 3: b=0.05$, $S E=0.04, p=.237)$ or Black students (W1: $b=0.00, S E=0.04, p=.940 ; \mathrm{W} 2: b=-0.02, S E=$ $0.05, p=.678 ; \mathrm{W} 3: b=-0.04, S E=0.04, p=.394)$ at any of the three waves. 
Median MCAT score of admitted students did not significantly predict belonging $(b=$ $0.00, S E=0.02), t(719)=0.05, p=.958$. Median GPA of admitted students did not significantly predict belonging $(b=-0.32, S E=0.63), t(719)=-0.51, p=.609$.

\section{Perceived Residency Competitiveness}

We anticipated that Black students would perceive themselves to be less competitive for residency than White students, yet this difference failed to meet our Bonferroni-corrected alpha level and the pattern of the means indicated a trend of Black students $(M=4.24, S E=0.08)$ perceiving themselves as more competitive for residency than White students $(M=4.13, S E=$ $0.09), F(1,719)=4.00, p=.046$. The main effect of frequency of self-affirmation was significant, such that more frequent self-affirmation was associated with a reduction in perceived residency competitiveness $(b=-0.21, S E=0.07), t(719)=-2.95, p=.003, R^{2}=.011$. Wave of data collection did not significantly predict perceived residency competitiveness, $F(2,719)=$ $1.98, p=.139$. Perceived medical residency competitiveness at $\mathrm{W} 1(M=4.30, S E=0.06), \mathrm{W} 2$ $(M=4.19, S E=0.07)$, and $\mathrm{W} 3(M=4.07, S E=0.07)$ were roughly equivalent.

The interaction between frequency of self-affirmation and student race did not reach our Bonferroni-corrected alpha level, $F(1,719)=4.08, p=.044, R^{2}=.006$. However, because this effect was nearly significant we followed-up this interaction by examining simple slopes.

Follow-up simple slope analyses indicated that frequency of self-affirmation did not significantly predict perceived residency competitiveness among White students $(B=0.02, S E=0.06), t(719)$ $=0.27, p=.789$. In contrast, among Black students, increased frequency of self-affirmation 
significantly predicted a reduction in perceived residency competitiveness $(B=-0.16, S E=0.06)$, $t(719)=-2.61, p=.009$.

The interaction between student race and wave of data collection also was not statistically significant, $F(2,719)=0.74, p=.478$, nor was the interaction between wave of data collection and frequency of self-affirmation, $F(2,719)=1.64, p=.195$. Furthermore, the three-way interaction between student race, wave of data collection, and frequency of self-affirmation was not statistically significant, $F(2,719)=1.03, p=.359$.

Median MCAT score of admitted students significantly predicted perceived residency competitiveness $(b=0.14, S E=0.03), t(719)=4.70, p<.001$. Median GPA of admitted students did not significantly predict perceived residency competitiveness $(b=0.83, S E=0.99), t(719)=$ $0.85, p=.398$.

\section{Residency Goal Stability}

In the model replacing the condition variable with self-affirmation frequency the effect of student race on likelihood of changing residency goals was still statistically significant, such that Black students were more likely to report changed residency goals ( robability $=.40, S E=.04$ ) than White students (probability $=.19, S E=.04), F(1,414)=22.25, p<.001, O R=5.36$. The main effect of frequency of self-affirmation was also significant, such that as frequency of selfaffirmation increased likelihood of reporting changed residency goals decreased, $F(1,414)=$ $7.42, p=.007$. However, these main effects were qualified by an interaction between student race and frequency of self-affirmation, $F(1,414)=9.38, p=.002$. Examination of the simple slopes indicated that among Black students, as frequency of self-affirmation increased likelihood 
reporting changed residency goals significantly decreased, $t(414)=-4.00, p<.001, O R=0.58$. In contrast, among White students frequency of self-affirmation was unrelated to the likelihood of reporting changed residency goals, $t(414)=.28, p=.778, O R=1.04$. Main effects of time point, university median MCAT score, and university median GPA of admitted students remained the same in this model.

\section{Discussion}

Self-affirmation interventions have been found to buffer the performance and well-being of Black students against the pernicious effects of stereotype threat and related hostile climates in several educational settings and populations (e.g., Cohen et al., 2006; Cohen et al., 2009; Cohen \& Sherman, 2014; Easterbrook et al., 2021; Sherman \& Cohen, 2006). Such interventions offer promising avenues to address the antagonistic environments Black students face in medical school settings, and ultimately, racial disparities in healthcare. Using a longitudinal field experiment, we tested whether a self-affirmation intervention would extend to a novel population and setting by protecting the well-being, belonging, career self-efficacy, and residency goal stability of Black medical students in the US. We did not find evidence that the self-affirmation intervention increased medical students' well-being and sense of belonging. Neither Black nor White US medical students reported changes in their well-being as a function of the intervention across the three time-points. However, we did find evidence that the intervention influenced Black students' residency goal stability. In the control condition, Black (compared to White) students' residency goals were less stable over time, but this gap was eliminated for Black students in the intervention condition.

Black medical students tend to underestimate their residency competitiveness relative to White students (Aagaard et al., 2005), which may lead them to be less likely to pursue highly 
selective residencies. For this reason, we were interested in students' judgments of their competitiveness for medical residency programs. We reasoned that, if self-affirmation decreased Black students' perceived threat in medical school, they might subsequently perceive a highly selective residency to be more obtainable. Yet, Black compared to White medical students did not show deficits in their perceived residency competitiveness, and surprisingly, Black medical students who self-affirmed showed some evidence of reduced perceived residency competitiveness relative to Black students who did not self-affirm. We elaborate on possible interpretations of this finding later in this discussion.

Overall, the results of our exploratory analysis indicated that Black students' residency goals were less stable over time than White students', but the intervention eliminated this racial gap. Moreover, when we tested the effect of the frequency of self-affirmation on residency stability we found the same general pattern of results - as frequency of self-affirmation increased Black students' residency goal instability decreased. These findings support the idea that selfaffirmation can facilitate goal pursuit in a medical residency choice context, closing the observed racial gap in residency goal stability.

We observed several patterns in our data that are consistent with prior stereotype threat and Black medical student well-being literature. For instance, overall, Black medical students reported more fatigue than White medical students. The amplified fatigue among Black medical students is compatible with research that indicates Black students in higher education, more broadly, experience heightened fatigue in predominantly White colleges (Smith et al., 2011). Black medical students also reported less belonging than White medical students, which is consistent with the evidence that Black students tend to feel like they do not belong in educational contexts (e.g., Walton \& Cohen, 2007). The racial disparities in fatigue and 
belonging among students in medical school are potentially indicative of the corrosive effects of stereotype threat and racial stressors for Black students (Hardeman et al., 2016; Perry et al., 2016). With the current study, however, we have mixed evidence that the self-affirmation intervention attenuated the negative psychological consequences that the Black students in our sample experienced when attending medical school.

We found some notable trends over time for students, overall. Consistent with prior literature (e.g., Carmel \& Bernstein, 1990; Smith et al., 2007), medical students across conditions reported increased anxiety over their second year of medical school. Students' perceptions that they would be competitive for residency also significantly declined from the beginning to the end of their second year of medical school.

Taken together, it remains somewhat unclear whether this particular implementation of the self-affirmation intervention ultimately benefits Black medical students in the US (and whether the outcomes tested here best capture the effects of the intervention), particularly those who are experiencing threats to their self-integrity. Although the beneficial effects of selfaffirmation interventions on the well-being of at-risk populations beyond medical students have been observed in several previous studies (e.g., Cohen et al., 2006; Cohen et al., 2009; Cohen et al., 2014; Sherman et al., 2006), the effectiveness of self-affirmation interventions are conditional (Binning \& Browman, 2020; Easterbrook \& Hadden, 2020) and do not always persist over time due to several possible constraints (see Cohen et al., 2014; Sherman et al., 2020). Some of the potential constraints relevant to the current study include timing, context, defensiveness, and awareness.

Concerning the timing, the intervention might have come too late, because it was administered in the second year of medical school. Some evidence suggests that self-affirmation 
interventions are most effective when they are introduced when the self-integrity threat first emerges, before defensive responding to that threat is initiated, or before decrements in efficacy and performance are evident (Briñol et al., 2007; Critcher et al., 2010; Cook et al., 2012; Ferrer \& Cohen, 2019; Sherman et al., 2020; Wu et al., 2021). Cook et al. (2012) found that early timing of the self-affirmation intervention-even by two weeks-was more important for improving achievement than the dosage of subsequent "booster shot" interventions. Cook and colleagues (2012) suggest that to disrupt the recursive cycle that undermines outcomes, intervening early in the process decreases the compounding influence that early failures may have on later outcomes. Students' early negative experiences in medical school may have undermined the potential positive effects of the intervention since it was administered in their second year. Further, Ferrer and Cohen (2019) theorize that, to alleviate the threat, the affirmation intervention should occur near the time the threat emerges and that students should have the objective resources to benefit from affirming, such as learning opportunities and social support (e.g., Cohen et al., 2017; Sherman et al., 2020). Future studies should examine whether implementing the self-affirmation intervention at the very start of medical school (i.e., the beginning of the first year) would be more effective.

Context is perhaps another crucial constraint. Recent work has highlighted the moderating role of context in the effectiveness of the self-affirmation interventions (Protzko \& Aronson, 2016), finding that self-affirmation interventions may be ineffective for individuals who represent an especially small minority group in that context. In the current study, Black medical students were grossly underrepresented at their institutions, making up an average of just $6 \%$ of their matriculating class, which is consistent with the percentage of Black students at predominantly White medical schools, nationwide (AAMC, 2019; Lett et al., 2019). Therefore, 
due to low levels of racial diversity, on average, a self-affirmation intervention may not be optimally effective in medical schools lacking racial diversity. Some medical school contexts may not readily afford Black students the benefits of a values affirmation. Walton and Yeager (2020) outline that social psychological interventions aimed at adapting students' way of thinking can only be successful if the contexts in which the students find themselves permit that thinking to be plausible. For instance, if an intervention leads students to believe that a feeling of not belonging is normal but will decrease over time, yet actual belonging opportunities in their contexts are largely absent, the effectiveness of the intervention will likely be undermined. Thus, predominantly White medical school contexts without adequate racial belonging opportunities may not readily afford Black students the ability to affirm their non-academic values.

We must note that conclusions of the utility of self-affirmation interventions in medical schools cannot yet be drawn, primarily because our investigation did not focus on academic performance outcomes (such as grades or completion rates) and the novelty of the implementation. Rather, we studied the effect of self-affirmation on psychological variables traditionally viewed as intermediate or process indicators of performance outcomes. However, we did find the intervention to be effective at promoting residency goal stability for Black students over time — an outcome variable more similar to distal performance indicators (suggesting the intervention may have had positive influences on goal stability). Further, in order to increase the likelihood that we would successfully recruit a substantial proportion of Black medical students across the 50 institutions, our study implemented a number of methods that may have affected the efficacy of the intervention. The intervention was administered via an online format, with a self-selected sample, and delivered from a medical research entity, rather than the students' educators directly (Easterbrook et al., 2021; Smith et al., 2021). Although 
similar formats were previously utilized in self-affirmation intervention studies, the majority of these studies were focused on reducing unhealthy behaviors (e.g., alcohol usage, smoking), and the findings have been mixed (Fielden et al., 2016; Norman et al., 2018; Taber et al., 2019).

Other recent studies (e.g., Borman et al., 2019) have employed longer and more involved, in-person, self-affirmation interventions (e.g., 20 minute in-class activity in which they selected and wrote about 2 or 3 values), which could be helpful to consider for future interventions with medical students. With regard to the sample opting to participate, it is plausible that those who opted out were the participants that would have most benefited from the task. With regard to delivery, the intervention effectiveness might be undermined if it is perceived as a research-led activity, rather than an instructional exercise led by the professors (Easterbrook et al., 2021; Smith et al., 2021). Teacher-led self-affirmation builds a sense of rapport and support among students of their instructors, contributing to greater academic engagement (Smith et al., 2021). In another study, a values affirmation intervention supported by the administration with a different graduate student population (i.e., women in business school) was effective (Kinias \& Sims, 2016). Furthermore, the exact same value affirmation exercise was administered at each wave after the outcome measurements. Because we did not vary the version of intervention at each wave, as with previous work, it is possible that participants may have found the prompt less engaging over time, therefore limiting its effect. Finally, measuring the outcomes (e.g., belonging, self-efficacy) before the task may have prevented the measurement of any of the immediate effects of the task. Future work should consider testing the intervention in medical schools using more common implementation procedures (e.g., in-person values affirmation writing tasks directed by students' instructors and measurement of GPA, retention, completion, and post-medical school success). 
We also must consider the possibility that the intervention backfired or had mixed effects. Walton and Wilson (2018) contend that when people do not adequately value achievement goals, affirmation interventions can help them restructure their thinking to focus on valuing achievement goals; however, when people already highly value achievement goals and are motivated by self-threats, the affirmation may be demotivating when they experience difficulty or failure. That is, because self-integrity threat sometimes promotes adaptive behavior, alleviating that threat through self-affirming may unintentionally undermine the motivation for the adaptive behavior (Sherman et al., 2020; Walton \& Wilson, 2018). For example, when experiencing failure, values affirmations can lead people to devalue their achievement goals by accepting that the goal is unattainable (Vohs et al., 2013). Because self-affirmation protects selfintegrity, thus making affirmed people less defensive to negative information about the self, affirmed individuals are more open to interpreting task difficulty or failure as lacking efficacy. Students who matriculate into medical school have already succeeded through a competitive selection process that requires valuing achievement goals despite self-threats. For Black students who already may have been motivated to persist to protect their self-integrity, the intervention may have reduced their motivation to persist and led them to interpret setbacks as indicative of their ability. This case would suggest that the intervention may have backfired and undermined their efficacy.

This reasoning is consistent with the Zone Model of Threat (Binning \& Browman, 2020), that theorizes that academic performance is highest when students identify with the domain (or domain value) and feel they have the personal and institutional resources to perform (or performance expectancies). Interventions that fail to optimally facilitate both components can have effects that are null or backfire (Binning \& Browman, 2020). If an intervention moves 
students' expectancies of performance to be greater than their value of the domain, this can lead to a sense of overconfidence and underperformance. Conversely, if an intervention leads students' domain value to be greater than performance expectancies, this can result in a sense of inadequacy and underperformance. To avoid effects that are null or backfire, researchers are recommended to first assess students' threat in domain value and their performance expectancies and then tailor the interventions to each student's needs for those components (Binning \& Browman, 2020).

Another possible explanation for the unexpected perceived competitiveness finding is that the self-affirmation intervention may have reduced students' defensiveness to threatening information (see Sherman \& Hartson, 2011, for a review). In the competitive context of medical school, a student admitting that they are not yet competitive for prestigious medical residencies can perhaps be construed as threatening. The self-affirmation intervention may have allowed students to consider that there is more room for growth, thereby rating themselves as being relatively less competitive for residencies. Further, the intervention may have permitted students to acknowledge the systemic barriers that disadvantage Black students from succeeding in medical training. Considering these possibilities, the intervention may have had a positive influence on Black students' acceptance of potentially threatening information that can ultimately help them improve and attribute systemic disadvantages to discrimination rather than personal failings. This interpretation is consistent with the current findings, in that Black students who self-affirmed more frequently rated themselves significantly lower in perceived residency competitiveness. Although there is some evidence that this may simply be a result of a randomization failure (since effects in our models were wave invariant), examination of the correlations between Black students' self-affirmation frequency and perceived residency 
competitiveness indicate that they were unrelated at W1 $(r=-.07)$ and only became correlated following the intervention ( $r \mathrm{~s}=-.19)$. This suggests that the perceived residency competitiveness findings are not entirely an artifact of initial between group differences, such that they also represent effects of self-affirming. Further research is needed to better understand the role of self-affirmations on students' self-efficacy.

Another possible constraint to consider is awareness of the self-affirmation intervention process. The effectiveness of self-affirmation interventions can be undermined if participants are aware of the aim of the intervention (Silverman et al., 2013). Medical students may be more aware of and less compliant with aims to influence them than are adolescents and undergraduates (e.g., Sears, 1986; Peterson \& Murunka, 2014), given their relative knowledge and experiences. Black students may have been especially suspicious of any researcher's attempt to influence them, given the vast underrepresentation of Black students in US medical schools. Such awareness could reduce the intervention's effectiveness.

The intervention's promotion of residency goal stability over time for Black students appears to be evidence of the benefit of self-affirmation on goal perseverance. Prior findings suggest that self-affirmation can facilitate goal pursuit if resources are available to reach those goals. However, self-affirmation can also help people recognize when is it best to disengage with goals that are unworthy or unachievable due to a lack of resources (e.g., Binning \& Browman, 2020; Cohen \& Sherman, 2014; Schmeichel \& Vohs, 2009; Sherman et al., 2020; Vohs et al., 2013; Walton \& Wilson, 2018). Our findings suggest that goal stability was facilitated for Black students who self-affirmed. Yet, it is unclear whether this stability in residency goals is necessarily valuable for students. Further research is warranted to determine whether residency goal stability over the course of medical school is related to positive outcomes. The current 
findings contribute to the ongoing theoretical discussion of whether self-affirmation promotes goal perseverance and the practical considerations of which outcomes we should consider when measuring the influence of self-affirmation interventions in professional school settings.

Given our study's findings, we have a few suggestions for future researchers interested in applying self-affirmation interventions for medical student populations. First, we recommend testing whether an earlier implementation of the intervention (closer to the emergence of threat) would prove more useful, such as at the beginning of medical school training or even when undergraduates show interest in a pre-medicine career track. Second, researchers should further explore the role of context and specifically target students in contexts that would most likely afford Black students to benefit from affirming their values, such as medical schools with greater representation of Black students and faculty and resources for Black students. The structural barriers in many predominantly White institutions may be too constraining for the intervention to be beneficial for Black students as it could be. Third, researchers should exercise great caution when implementing these affirmation interventions to avoid unintended effects. More research is needed to determine whether self-affirmation is beneficial when motivation to disconfirm stereotypes is a key driver of performance. Indeed, more literature, in general, is needed to understand what role self-affirmation plays in educational contexts wherein the students already excel academically (such as Black medical students) but still experience self-threats and racial stressors that potentially undermine their well-being, belonging, and self-efficacy, and ultimately, their persistence and professional success. Lastly, researchers should consider alternative ways to engage medical students with a self-affirmation intervention that is developmentally and contextually appropriate. Medical students might be especially responsive if they were brought into the intervening process and trained on how to activate self-affirmation 
processes as a preventative strategy to deal with self-integrity threats for themselves as well as their future patients. More research should examine the ways participants could serve as active agents in affirming the self in adaptive ways.

Although we focused on intervening on individual level construal and motivational processes that influence academic performance, there are many other factors beyond managing psychological threats that contribute to racial disparities in medical school achievement that are unlikely to be influenced by the intervention. For example, Black students are disproportionately affected by student loan debt (Dugger et al., 2013). Structural barriers, such as the financial costs of medical school, may put additional strains on Black medical students that would most benefit from structural-level interventions, such as student debt forgiveness and more resources for Black students to fund their medical education. Racial disparities in student debt are a part of a broader structural context of systemic racism in the policies and practices of the healthcare industry and academic medicine (Feagin \& Bennefield, 2014). Individual-level interventions should be pursued as a complementary — and not a replacement — approach to promote racial equity in medical school achievement.

For over a decade, increasing the racial diversity of the American healthcare workforce has been strongly recommended as an essential strategy for reducing racial disparities in healthcare (e.g., Klonoff, 2009; Nelson, 2002; Smedley et al., 2004; Sullivan, 2004). Yet, little progress has been made toward this goal. The race-related stressors that Black students experience during medical school-including greater discrimination, lower psychological wellbeing, and less belonging than White students-contribute to this problem. To increase the representation of Black providers in healthcare, efforts to mitigate these stressors are necessary. We anticipated that a self-affirmation intervention might offer a potential shield to protect the 
well-being of Black students when facing race-related stressors during their medical education.

However, more research is needed to determine how social psychological interventions-such as affirming the self—can best serve students facing racial stressors in medical school. Such research would be critical in increasing the representation of Black providers in healthcare and improving the quality of care for Black patients.

\section{Conclusion}

In the first known field experiment of a self-affirmation intervention in the US medical school setting, we attempted to protect the psychosocial health of Black medical students from the negative consequences of stereotype threat. Consistent with the effects of stereotype threat, we observed clear indications that, overall, Black medical students experienced greater decrements in their psychological well-being, sense of belonging, and residency goal stability over the second year of medical school, compared to White medical students. While our study found no beneficial effect of the self-affirmation intervention on measures of Black medical students' psychological well-being, belonging, or career self-efficacy, we did observe that the intervention eliminated racial differences in residency goal stability. Future research should investigate whether these effects would replicate in other contexts with medical students (e.g., earlier in medical school) and the extent to which the medical student population is receptive to self-affirmation interventions with other outcome measures (e.g., academic performance).

In 2018, Campbell and colleagues called for continued research on Black medical student specialty choice, noting that such research might “... move the United States closer to workforce and health equity." They further concluded that "dismantling systems that [contribute to the disproportionate disadvantages for some, while privileging others] requires acknowledging past inequities and promoting equity in the future" (Campbell et al., 2018, p. 346). Consistent with 
this call, we believe that future research should further explore the psychological experiences and stressors that contribute to the gaps we observed in Black medical students' sense of belonging and residency goal stability, and potential ways we can ameliorate them. The current work emphasizes the importance of developing strategies that can foster an environment in which all medical students can thrive, which is critical to addressing the vast underrepresentation of Black medical providers in the U.S. healthcare system, and ultimately remediating persistent racial health disparities. 


\section{References}

Aagaard, E. M., Julian, K., Dedier, J., Soloman, I., Tillisch, J., \& Perez-Stable, E. J. (2005).

Factors affecting medical students' selection of an internal medicine residency program. Journal of the National Medical Association, 97, 1264-1270.

AAMC (2019). Diversity in Medicine: Facts and Figures in 2019. Retrieved from https://www.aamc.org/news-insights/us-medical-school-enrollment-rises-30 in April, 2020.

AAMC (2019). Diversity in Medicine: Facts and Figures in 2019. Retrieved from https://www.aamc.org/data-reports/workforce/report/diversity-facts-figures in December, 2019.

AAMC (2016). Matriculating Student Questionnaire. Retrieved from https:/www.aamc.org/system/files/reports/1/msq2016report.pdf, in January, 2020.

AAMC (2018) Residency Match: The 7 most competitive medical specialties. Retrieved from: https://www.ama-assn.org/residents-students/specialty-profiles/residency-match-7-mostcompetitive-medical-specialties in January, 2020.

Acheampong, C., Davis, C., Holder, D., Averett, P., Savitt, T., \& Campbell, K. (2019). An exploratory study of stress coping and resiliency of black men at one medical school: A critical race theory perspective. Journal of Racial and Ethnic Health Disparities, 6(1), 214-219.

Aronson, J., Quinn, D. M., \& Spencer, S. J. (1998). Stereotype threat and the academic underperformance of minorities and women. In J. K. Swim \& C. Stangor (Eds.), Prejudice: The target's perspective (p. 83-103). Academic Press. 
Bandura, A. (1977). Self-efficacy: toward a unifying theory of behavioral change. Psychological review, 84(2), 191.

Bandura, A. (2010). Self-efficacy. The Corsini encyclopedia of psychology, 1-3.

Bair, A. N., \& Steele, J. R. (2010). Examining the consequences of exposure to racism for the executive functioning of Black students. Journal of Experimental Social Psychology, $46(1), 127-132$.

Binning, K. R., \& Browman, A. S. (2020). Theoretical, ethical, and policy considerations for conducting social-psychological interventions to close educational achievement gaps. Social Issues and Policy Review, 14(1), 182-216.

https://doi.org/10.1017/CBO9781107415324.004

Boatright, D., Ross, D., O’Connor, P., Moore, E., \& Nunez-Smith, M. (2017). Racial disparities in medical student membership in the Alpha Omega Alpha Honor Society. JAMA internal medicine, 177(5), 659-665.

Borman, G. D., Grigg, J., Rozek, C. S., Hanselman, P., \& Dewey, N. A. (2018). Self-affirmation effects are produced by school context, student engagement with the intervention, and time: Lessons from a district-wide implementation. Psychological Science, 29(11), $1773-1784$.

Borman G.D., Rozek, C.S., Pyne J., Hanselman, P. (2019) Reappraising academic and social adversity improves middle school students' academic achievement, behavior, and well-being PNAS, 116 (33) 16286-16291

Briñol, P., Petty, R. E., Gallardo, I., \& DeMarree, K. G. (2007). The effect of self-affirmation in nonthreatening persuasion domains: Timing affects the process. Personality and Social Psychology Bulletin, 33(11), 1533-1546. 
Butler, P. D., Longaker, M. T., \& Britt, L. D. (2008). Major deficit in the number of underrepresented minority academic surgeons persists. Annual Surgery, 248(5), 704-711. doi:10.1097/SLA.0b013e31817f2c30

Campbell, K. M., \& Rodríguez, J. E. (2018). Could more black doctors being in primary care specialties be the result of institutional racism?. Academic Medicine, 93(3), 346.

Carmel, S., \& Bernstein, J. (1990). Trait anxiety, sense of coherence and medical school stressors: Observations at three stages. Anxiety Research, 3(1), 51-60.

Cella, D., Yount, S., Rothrock, N., Gershon, R., Cook, K., Reeve, B., \& Rose, M. (2007). The Patient-Reported Outcomes Measurement Information System (PROMIS): progress of an NIH Roadmap cooperative group during its first two years. Medical care, 45(5 Suppl 1), S3-S11.

Cohen, G. L., Garcia, J., Apfel, N., \& Master, A. (2006). Reducing the racial achievement gap: A social-psychological intervention. Science, 313(5791), 1307-1310. doi:10.1126/science. 1128317

Cohen, G. L., Garcia, J., \& Goyer, J. P. (2017). Turning Point: Targeted, Tailored, and Timely Psychological Intervention. In A. J. Elliot, C. S. Dweck, \& D. S. Yeager (Eds.), Handbook of Competence and Motivation: Theory and Application (p. 657-686). The Guilford Press.

Cohen, G. L., Garcia, J., Purdie-Vaughns, V., Apfel, N., \& Brzustoski, P. (2009). Recursive processes in self-affirmation: Intervening to close the minority achievement gap. Science, 324(5925), 400-403. Doi: 324/5925/400 [pii] 10.1126/science.1170769 
Cohen, G. L., \& Sherman, D. K. (2014). The psychology of change: Self-affirmation and social psychological intervention. Annual Review of Psychology, 65, 333-371. Doi: 10.1146/annurev-psych-010213-115137

Cohen, J. J., Gabriel, B. A., \& Terrell, C. (2002). The case for diversity in the health care workforce. Health Affairs, 21(5), 90-102.

Cook, J. E., Purdie-Vaughns, V., Garcia, J., \& Cohen, G. L. (2012). Chronic threat and contingent belonging: protective benefits of values affirmation on identity development. Journal of Personality and Social Psychology, 102(3), 479.

Council on Graduate Medical Education (US), United States. Health Resources, \& Services Administration. (2005). Minorities in Medicine: An Ethnic and Cultural Challenge for Physician Training: an Update (Vol. 17). US Department of Health and Human Services, Health Resources and Services Administration.

Cressey, D. (2008). Experts point to concerning disparities within MD-PhD programs. National Medicine, 14(10), 994. Doi: 10.1038/nm1008-994a

Critcher, C. R., Dunning, D., \& Armor, D. A. (2010). When self-affirmations reduce defensiveness: Timing is key. Personality and Social Psychology Bulletin, 36(7), 947959.

de Jong, E. M., Jellesma, F. C., Koomen, H. M., \& de Jong, P. F. (2016). A values-affirmation intervention does not benefit negatively stereotyped immigrant students in the Netherlands. Frontiers in Psychology, 7, 691.

Demirören, M., Turan, S., \& Öztuna, D. (2016). Medical students’ self-efficacy in problembased learning and its relationship with self-regulated learning. Medical education online, 21(1), 30049 . 
Diaz, T., Navarro, J. R., \& Chen, E. H. (2020). An institutional approach to fostering inclusion and addressing racial bias: implications for diversity in academic medicine. Teaching and Learning in Medicine, 32(1), 110-116.

Dugger, R. A., El-Sayed, A. M., Dogra, A., Messina, C., Bronson, R., \& Galea, S. (2013). The color of debt: Racial disparities in anticipated medical student debt in the United States. PloS one, 8(9), e74693.

Easterbrook, M J., Sherman, D., \& Harris (2021). Self-affirmation in education. Journal of Social Issues.

Easterbrook, M. J., \& Hadden, I. R. (2020). Tackling educational inequalities with social psychology: Identities, contexts, and interventions. Social Issues and Policy Review. https://doi.org/10.1111/sipr.12070

Edmond, M. B., Deschenes, J. L., Eckler, M., \& Wenzel, R. P. (2001). Racial bias in using USMLE step 1 scores to grant internal medicine residency interviews. Academic Medicine, 76(12), 1253-1256.

Edwards, L. J., Muller, K. E., Wolfinger, R. D., Qaqish, B. F., \& Schabenberger, O. (2008). An R2 statistic for fixed effects in the linear mixed model. Statistics in Medicine, 27(29), 6137-6157.

Emanuel, A. S., Howell, J. L., Taber, J. M., Ferrer, R. A., Klein, W. M., \& Harris, P. R. (2018). Spontaneous self-affirmation is associated with psychological well-being: Evidence from a US national adult survey sample. Journal of Health Psychology, 23(1), 95-102.

Epton, T., Harris, P. R., Kane, R., van Koningsbruggen, G. M., \& Sheeran, P. (2015). The impact of self-affirmation on health-behavior change: A meta-analysis. Health Psychology, 34(3), 187. 
Espaillat, A., Panna, D. K., Goede, D. L., Gurka, M. J., Novak, M. A., \& Zaidi, Z. (2019). An exploratory study on microaggressions in medical school: What are they and why should we care? Perspectives on Medical Education, 1-9.

Feagin, J., \& Bennefield, Z. (2014). Systemic racism and US health care. Social Science \& Medicine, 103, 7-14.

Ferrer, R. A., \& Cohen, G. L. (2019). Reconceptualizing self-affirmation with the trigger and channel framework: Lessons from the health domain. Personality and Social Psychology Review, 23(3), 285-304.

Fielden, A. L., Sillence, E., Little, L., \& Harris, P. R. (2016). Online self-affirmation increases fruit and vegetable consumption in groups at high risk of low intake. Applied Psychology: Health and Well-Being, 8(1), 3-18.

Gibbons, F. X., O'Hara, R. E., Stock, M. L., Gerrard, M., Weng, C. Y., \& Wills, T. A. (2012). The erosive effects of racism: reduced self-control mediates the relation between perceived racial discrimination and substance use in African American adolescents. Journal of Personality and Social Psychology, 102(5), 1089.

Hadden, I. R., Easterbrook, M. J., Nieuwenhuis, M., Fox, K. J., \& Dolan, P. (2019). Selfaffirmation reduces the socioeconomic attainment gap in schools in England. British Journal of Educational Psychology, 1-20. https://doi.org/10.1111/bjep.12291

Hardeman, R. R., Przedworski, J. M., Burke, S., Burgess, D. J., Perry, S., Phelan, S., Dovidio, J. F., van Ryn, M. (2016). Association between perceived medical school diversity climate and change in depressive symptoms among medical students: A report from the Medical Student CHANGE Study. Journal of the National Medical Association, 108(4), 225-235. 
Harris, P. R., Mayle, K., Mabbott, L., \& Napper, L. (2007). Self-affirmation reduces smokers' defensiveness to graphic on-pack cigarette warning labels. Health Psychology, 26(4), 437.

Havranek, E. P., Hanratty, R., Tate, C., Dickinson, L. M., Steiner, J. F., Cohen, G., \& Blair, I. A. (2012). The effect of values affirmation on race-discordant patient-provider communication. Archives of Internal Medicine, 1-6. doi:10.1001/2013.jamainternmed.258

Howell, A. J. (2017). Self-affirmation theory and the science of well-being. Journal of Happiness Studies, 18(1), 293-311.

Huff, K. L., \& Fang, D. (1999). When are students most at risk of encountering academic difficulty? A study of the 1992 matriculants to US medical schools. Academic medicine: journal of the Association of American Medical Colleges, 74(4), 454-460.

Jeffe, D. B., Yan, Y., \& Andriole, D. A. (2012). Do research activities during college, medical school, and residency mediate racial/ethnic disparities in full-time faculty appointments at U.S. medical schools? Academic Medicine, 87(11), 1582-1593. doi:10.1097/ACM.0b013e31826e3297

Johns, M., Schmader, T., \& Martens, A. (2005). Knowing is half the battle: Teaching stereotype threat as a means of improving women's math performance. Psychological Science, 16(3), 175-179. doi:10.1111/j.0956-7976.2005.00799.x

Keough, K. A., \& Markus, H. R. (1998). The role of the self in building the bridge from philosophy to biology. Psychological Inquiry, 9(1), 49-53. 
Kinias, Z., \& Sim, J. (2016). Facilitating women's success in business: Interrupting the process of stereotype threat through affirmation of personal values. Journal of Applied Psychology, 101(11), 1585.

Klonoff, E. A. (2009). Disparities in the provision of medical care: An outcome in search of an explanation. Journal of Behavioral Medicine, 32(1), 48.

Lett, L. A., Murdock, H. M., Orji, W. U., Aysola, J., \& Sebro, R. (2019). Trends in racial/ethnic representation among US medical students. JAMA Network Open, 2(9). doi: 10.1001/jamanetworkopen.2019.10490

Lewis Jr, N. A., \& Sekaquaptewa, D. (2016). Beyond test performance: A broader view of stereotype threat. Current Opinion in Psychology, 11, 40-43.

Liebschutz, J. M., Darko, G. O., Finley, E. P., Cawse, J. M., Bharel, M., \& Orlander, J. D. (2006). In the minority: black physicians in residency and their experiences. Journal of the National Medical Association, 98(9), 1441.

Logel, C., \& Cohen, G. L. (2012). The role of the self in physical health: Testing the effect of a values-affirmation intervention on weight loss. Psychological Science, 23(1), 53-55.

Low, D., Pollack, S. W., Liao, Z. C., Maestas, R., Kirven, L. E., Eacker, A. M., \& Morales, L. S. (2019). Racial/ethnic disparities in clinical grading in medical school. Teaching and learning in medicine, 31(5), 487-496.

Mavis, B. (2001). Self-efficacy and OSCE performance among second year medical students. Advances in health sciences education, 6(2), 93-102.

Miyake, A., Kost-Smith, L. E., Finkelstein, N. D., Pollock, S. J., Cohen, G. L., \& Ito, T. A. (2010). Reducing the gender achievement gap in college science: A classroom study of values affirmation. Science, 330(6008), 1234-1237. doi:330/6008/1234 [pii] 


\subsection{6/science. 1195996}

Mortensen, S. J., Menard, E. J., Olson, E. B., Deng, H. C., Hasserjian, R., Black-Schaffer, W. S., ... \& Nazarian, R. M. (2019). Characterization of applicants for residency training in pathology: Does diversity exist?. Annals of Diagnostic Pathology, 40, 23-25.

Murphy, M. C., Steele, C. M., \& Gross, J. J. (2007). Signaling threat: How situational cues affect women in math, science, and engineering settings. Psychological Science, 18(10), 879885. doi:10.1111/j.1467-9280.2007.01995.x

Nelson, A. (2002). Unequal treatment: confronting racial and ethnic disparities in health care. Journal of the National Medical Association, 94(8), 666-668.

Nelson, S. K., Fuller, J. A., Choi, I., \& Lyubomirsky, S. (2014). Beyond self-protection: Selfaffirmation benefits hedonic and eudaimonic well-being. Personality and Social Psychology Bulletin, 40(8), 998-1011.

Norman, P., Cameron, D., Epton, T., Webb, T. L., Harris, P. R., Millings, A., \& Sheeran, P. (2018). A randomized controlled trial of a brief online intervention to reduce alcohol consumption in new university students: Combining self-affirmation, theory of planned behaviour messages, and implementation intentions. British Journal of Health Psychology, 23(1), 108-127.

Nunez-Smith, M., Pilgrim, N., Wynia, M., Desai, M. M., Bright, C., Krumholz, H. M., \& Bradley, E. H. (2009). Health care workplace discrimination and physician turnover. Journal of the National Medical Association, 101(12), 1274-1282.

Nguyen, H. H. D., \& Ryan, A. M. (2008). Does stereotype threat affect test performance of minorities and women? A meta-analysis of experimental evidence. Journal of Applied Psychology, 93(6), 1314. 
Odom, K. L., Roberts, L. M., Johnson, R. L., \& Cooper, L. A. (2007). Exploring obstacles to and opportunities for professional success among ethnic minority medical students. Academic Medicine, 82(2), 146-153.

Perry, S. P., Hardeman, R., Burke, S. E., Cunningham, B., Burgess, D. J., \& van Ryn, M. (2016). The impact of everyday discrimination and racial identity centrality on African American medical student well-being: A report from the Medical Student CHANGE Study. Journal of Racial and Ethnic Health Disparities, 3(3), 519-526. doi:10.1007/s40615-015-0170-3

Peterson, R. A., \& Merunka, D. R. (2014). Convenience samples of college students and research reproducibility. Journal of Business Research, 67(5), 1035-1041.

Phelan, S. M., Dovidio, J. F., Puhl, R. M., Burgess, D. J., Nelson, D. B., Yeazel, M. W., ... \& Van Ryn, M. (2014). Implicit and explicit weight bias in a national sample of 4,732 medical students: the medical student CHANGES study. Obesity, 22, 1201-1208.

Protzko, J., \& Aronson, J. (2016). Context moderates affirmation effects on the ethnic achievement gap. Social Psychological and Personality Science, 7(6), 500-507. doi: $10.1177 / 1948550616646426$

Richeson, J. A., \& Trawalter, S. (2005). Why do interracial interactions impair executive function? A resource depletion account. Journal of Personality and Social Psychology, $88(6), 934$.

Sanchez, J. P., Castillo-Page, L., Spencer, D. J., Yehia, B., Peters, L., Freeman, B. K., \& LeeRey, E. (2011). Commentary: The building the next generation of academic physicians initiative: engaging medical students and residents. Academic Medicine, 86(8), 928-931. doi:10.1097/ACM.0b013e31822220df 
Schmeichel, B. J., \& Vohs, K. (2009). Self-affirmation and self-control: affirming core values counteracts ego depletion. Journal of Personality and Social Ppsychology, 96(4), 770.

Sears, D. O. (1986). College sophomores in the laboratory: Influences of a narrow data base on social psychology's view of human nature. Journal of Personality and Social Psychology, $51(3), 515$.

Sherman, D. K., Bunyan, D. P., Creswell, J. D., \& Jaremka, L. M. (2009). Psychological vulnerability and stress: The effects of self-affirmation on sympathetic nervous system responses to naturalistic stressors. Health Psychology, 28(5), 554.

Sherman, D. K., \& Cohen, G. L. (2006). The psychology of self-defense: Self-affirmation theory. Advances in Experimental Social Psychology, Vol 38, 38, 183-242. Doi: 10.1016/S00652601(06)38004-5

Sherman, D. K., Lokhande, M., Müller, T., \& Cohen, G. L. (in press). Self-affirmation Interventions. To appear in G. Walton and A. Crum (Eds.). Handbook of Wise Interventions: How Social-Psychological Insights Can Help Solve Problems.

Silverman, A., Logel, C., \& Cohen, G. L. (2013). Self-affirmation as a deliberate coping strategy: The moderating role of choice. Journal of Experimental Social Psychology, 49(1), 93-98.

Smedley, B. D., Butler, A. S., \& Bristow, L. R. (2004). In the nation's compelling interest: Ensuring diversity in the health care workforce: The National Academies Press.

Smith, C. K., Peterson, D. F., Degenhardt, B. F., \& Johnson, J. C. (2007). Depression, anxiety, and perceived hassles among entering medical students. Psychology, Health \& Medicine, 12(1), 31-39. 
Smith, E. N., Rozek, C. S., Manke, K. J., Dweck, C. S., \& Walton, G. M. (2021). Teacher-versus researcher-provided affirmation effects on students' task engagement and positive perceptions of teachers. Journal of Social Issues.

Smith, W. A., Yosso, T. J., \& Solórzano, D. G. (2011). Challenging racial battle fatigue on historically White campuses: A critical race examination of race-related stress. In C. A. Stanley (Ed.) Covert racism (pp. 211-237). Anker Publishing: Bolton, MA.

Spencer, S.J., Logel, C., \& Davies, P.G. (2016) Stereotype threat. Annual Review of Psychology $67,415-37$.

Steele, C. M. (1997). A threat in the air. How stereotypes shape intellectual identity and performance. American Psychologist, 52(6), 613-629.

Steele, C. M. (1988). The psychology of self-affirmation: Sustaining the integrity of the self. In Advances in Experimental Social Psychology (Vol. 21, pp. 261-302). Academic Press.

Steele, C. M., Spencer, S. J., \& Aronson, J. (2002). Contending with group image: The psychology of stereotype and social identity threat. Advances in Experimental Social Psychology, Vol 34, 34, 379-440. Doi: 10.1016/S0065-2601(02)80009-0

Sullivan, L. W. (2004). Missing persons: minorities in the health professions, a report of the Sullivan Commission on Diversity in the Healthcare Workforce.

Sweeney, A. M., \& Moyer, A. (2015). Self-affirmation and responses to health messages: A meta-analysis on intentions and behavior. Health Psychology, 34(2), 149.Taber, J. M., McQueen, A., Simonovic, N., \& Waters, E. A. (2019). Adapting a self-affirmation intervention for use in a mobile application for smokers. Journal of Behavioral Medicine, 42(6), 1050-1061. 
Tekian, A. (1998). Attrition rates of underrepresented minority students at the University of Illinois at Chicago College of Medicine, 1993-1997. Academic Medicine, 73(3), 336-338. van Ryn, Michelle \& Burke-Miller, Jane. (2000). The effect of patient race and socio-economic status on physicians' perceptions of patients. Social science \& Medicine, 50, 813-28.

van Ryn, M., Burgess, D., Malat, J., \& Griffin, J. (2006). Physicians' perceptions of patients’ social and behavioral characteristics and race disparities in treatment recommendations for men with coronary artery disease. American Journal of Public Health, 96, 351-7. van Ryn, M., Burgess, D. J., Dovidio, J. F., Phelan, S. M., Saha, S., Malat, J., Griffin, J. M., Fu, S. S., \& Perry, S. (2011). The Impact of Racism on Clinical Cognition, Behavior, and Clinical Decision Making. Du Bois Review: Social Science Research on Race, 8(1), $199-218$.

Vohs, K. D., Park, J. K., \& Schmeichel, B. J. (2013). Self-affirmation can enable goal disengagement. Journal of Personality and Social Psychology, 104(1), 14.

Walton, G. M., \& Cohen, G. L. (2007). A question of belonging: race, social fit, and achievement. Journal of Personality and Social Psychology, 92(1), 82.

Walton, G. M., \& Cohen, G. L. (2011). A brief social-belonging intervention improves academic and health outcomes of minority students. Science, 331, 1447-1451.

Walton, G. M., \& Spencer, S. J. (2009). Latent ability: Grades and test scores systematically underestimate the intellectual ability of negatively stereotyped students. Psychological Science, 20(9), 1132-1139.

Walton, G. M., \& Wilson, T. D. (2018). Wise interventions: Psychological remedies for social and personal problems. Psychological Review, 125(5), 617. 
Walton, G. M., \& Yeager, D. S. (2020). Seed and soil: Psychological affordances in contexts help to explain where wise interventions succeed or fail. Current Directions in Psychological Science, 29(3), 219-226.

Wijesekera, T. P., Kim, M., Moore, E. Z., Sorenson, O., \& Ross, D. A. (2019). All other things being equal: exploring racial and gender disparities in medical school honor society induction. Academic Medicine, 94(4), 562-569.

Woolf, K., McManus, I. C., Gill, D., \& Dacre, J. (2009). The effect of a brief social intervention on the examination results of UK medical students: a cluster randomised controlled trial. BMC Medical Education, 9(1), 35.

Wu et al., 2021. [Insert full reference here]. Journal of Social Issues. 


\section{Supplemental Materials}

\section{Exploratory Analyses}

Some social psychological interventions have been found to be less effective for students in contexts that do not afford opportunities for the intervention to work (e.g., Walton \& Yeager, 2020). Such opportunities in an educational context might include affirming instructors, peer social support, and a welcoming campus atmosphere. If medical school contexts do not permit Black students to benefit from affirming their values, then the effectiveness of the selfaffirmation intervention could be undermined. One way we can examine this possibility is to test whether the context affordances moderate the intervention's effectiveness. We measured students' reporting of being in a racially negative campus climate and suggest this variable could serve as a proxy for context affordance. That is, perceiving the medical school campus climate as being racially tense or hostile toward Black students would likely signal to Black students they are in a context that does not support their well-being and success. We expect that the intervention would be less effective for Black students in negative campus climates, because these contexts likely do not afford Black students opportunities to benefit from self-affirming.

We also considered the role of the centrality of student identity. Stereotype threat has been found to decrease identification with the educational domain (e.g., Woodcock et al., 2012). A strong medical student identity may allow for the self-affirmation intervention to be protective as these students are already highly motivated and invested in this identity. However, highly identified medical students who already strongly value educational goals may construe some threats as motivating rather than discouraging educational goal pursuit. If self-affirming alleviates threats that were motivating the pursuit of educational goals, the intervention may 
inadvertently lead to academic disengagement among students from those goals (e.g., Walton \& Wilson, 2018). Thus, for students who already value educational goals, such as those with central medical student identities, the intervention may buffer the threat that was motivating them to achieve, and may undermine their outcomes. Based on this reasoning, the centrality of medical student identity might enhance or undermine the intervention's effectiveness.

Among our supplemental variables, we measured students' reports of being in a racially negative campus climate and the centrality of their medical student identity. We explored whether these two variables would provide any evidence of moderation of the intervention's effectiveness. We tested whether the intervention was less effective at protecting Black students' sense of belonging and at ameliorating their fatigue in contexts that were unwelcoming or toxic for Black students. Belonging and fatigue appear to be the most relevant measured outcomes that would be related to Black students' experiences with a racially charged environment. We tested whether the intervention affects the perceived residency competitiveness for Black students depending on their medical student identity. Given that perceived residency competitiveness is a manifestation of how efficacious students see themselves in pursuit of educational goals, perceived residency competitiveness would seem most relevant to how central the medical student identity is to participants.

Negative campus climate was measured at Waves 2 and 3 of data collection with the following three items on a 7-point agreement scale (Cronbach's alphas $\left.=.75^{\mathrm{W} 2} \& .77^{\mathrm{W} 3}\right)$, from 1 (Strongly Disagree) to 7 (Strongly Agree): (1) "I have witnessed racial insensitivity from other students.", (2) "I have witnessed racial insensitivity from faculty.", and (3) "The interracial climate on this campus is tense." 
Medical student identity was measured at all three waves of collection with the following eight items on a 7-point agreement scale (Cronbach's alphas $=.77^{\mathrm{W} 1}, .77^{\mathrm{W} 2}, \& .79^{\mathrm{W} 3}$ ), from 1 (Strongly Disagree) to 7 (Strongly Agree): (1) “Overall, being a medical student has very little to do with how I feel about myself." (R), (2) "In general, being a medical student is an important part of my self-image.", (3) "I have a strong attachment to other medical students.", (4) “Being a medical student is an important reflection of who I am.", (5) "My destiny is tied to the destiny of other medical students.", (6) "Being a medical student is unimportant to my sense of what kind of person I am.” (R), (7) “Being a medical student is not a major factor in my social relationships." (R), and (8) "I have a strong sense of belonging to members of the medical student community."

We ran three exploratory analyses to test whether the effectiveness of the intervention differed depending upon Black students' negative campus climate and their medical student identity. We anticipated that among Black students, the more negative the campus climate, the less effective the intervention would be in affecting fatigue and sense of belonging. We also explored whether the effect of the intervention on perceived residency competitiveness for medical residencies among Black students would vary as a function of the centrality of their identity as a medical student.

The effect of the intervention on fatigue was not significantly moderated by negative campus climate and student race, $F(1,338)=0.21, p=.645$. All other fixed effects on fatigue were non-significant, $p$ 's $>.100$. 
For the belonging outcome, the effect of the interaction of the intervention, negative campus climate, and student race was also non-significant, $F(1,338)=0.22, p=.641$. We did, however, find that the main effect of negative campus climate $(F(1,338)=44.41, p<.001)$ and the interaction between negative campus climate and student race $(F(1,338)=17.81, p<.001)$ predicted reductions in belonging. Specifically, campus climate significantly predicted belonging for Black students $(t(338)=-8.00, p<.001)$ but not for White students $(t(338)=-1.66, p=.097)$. That is, the more Black (but not White) students reported a negative racial climate on their campus, the less they reported feeling like they belong in medical school. All other effects on belonging were non-significant, $p$ 's $>.051$.

For the perceived residency competitiveness outcome, the interaction between medical student identity, student race, and the intervention was non-significant, $F(1,707)=0.58, p=$ .448. We did, however, find a main effect of medical student identity, $F(1,707)=9.57, p=.002$, such that increases in medical student identities (regardless of student race or the intervention) predicted more perceived residency competitiveness. All other effects on perceived residency competitiveness were non-significant, $p$ 's $>.070$. 